\title{
Recent advances in electrochemical chitosan-based chemosen- sors and biosensors: applications in food safety
}

\author{
Rita Petrucci ${ }^{1}$, Mauro Pasquali ${ }^{1}$, Francesca Anna Scaramuzzo ${ }^{1}$ and Antonella Curulli 2,* \\ 1 Sapienza Università di Roma, Facoltà di Ingegneria Civile e Industriale, Dip. SBAI, Via del Castro \\ Laurenziano 7, 00161 Roma (Italy); rita.petrucci@uniroma1.it, mauro.pasquali@uniroma1.it, \\ francesca.scaramuzzo@uniroma1.it \\ 2 CNR SMN Istituto per lo Studio dei Materiali Nanostrutturati UOS Sapienza Via del Castro Laurenziano 7 \\ 00161 Roma (Italy); antonella.curulli@cnr.it \\ * Correspondence: antonella.curulli@cnr.it
}

\begin{abstract}
Chitosan is a biopolymer derived from chitin. It is a non-toxic, biocompatible, bioactive, and biodegradable polymer. Due to its properties, chitosan has found applications in several and different fields such as agriculture, food industry, medicine, paper fabrication, textile industry, and water treatment. In addition to these properties, chitosan has a good film-forming ability which allows it to be widely used for the development of sensors and biosensors. This review is focused on the use of chitosan for the formulation of electrochemical chemosensors. It also aims to provide an overview of the advantages of using chitosan as an immobilization platform for biomolecules by highlighting its applications in electrochemical biosensors. Finally, applications of electrochemical chitosan-based chemosensors and biosensors in food safety are illustrated.
\end{abstract}

Keywords: chitosan; nanomaterials; electrochemical chemosensors; electrochemical biosensors; food safety

\section{Introduction}

This review explores design, assembling and application of chitosan based electrochemical chemosensors and biosensors for the analysis of selected species/molecules involved in food screening and safety.

Food safety is an important critical issue for the modern food industry. Contaminants, bacteria, toxins, etc., can enter the food chain during the different steps of production. For example, they can accumulate in food during storage and/or are produced in the food by reaction with chemical compounds [1,2].

Moreover, food quality, i.e., screening of food contaminants/additives and analysis of food composition, is essential for food industries and consumers [2]. Some strict guidelines are provided by the regulatory agencies like United States Food and Drug Administration (USFDA) and the European Food Safety Authority (EFSA), which indicate the maximum levels for contaminants/additives in foodstuffs for guaranteeing the human health and consumer protection [3,4]. Presently, greatest part of the food analysis is carried out at the end of the production process using conventional techniques such as chromatography, mass spectrometry, ultraviolet detection, or fluorescence techniques either individually or in combination with other separation techniques [2]. These traditional approaches have several limitations. Firstly, since the analysis is performed at the end of the process, contaminated products can pass through the entire production chain before being examined and analysed and before the contamination can be evidenced. Second, these methods of analysis are demanding, expensive, time consuming, require large amount of samples, and skilled personnel, often restricting their use in the routine analyses.

In this context, the electrochemical methods offer a series of practical advantages as an easy procedure, not too expensive instruments, the possibility of miniaturization, 
besides good sensitivity, wide linear concentration range, readiness for real-time detection and reduced sensitivity to matrix effects $[2,5]$.

For these reasons, electrochemical chemosensors and biosensors have received an increasing attention and thereby have been widely used in food analysis for food safety.

In this review, we would like to outline the principal characteristics of electrochemical chemosensors and biosensors, in particular evidencing among them those chitosan-based, finally highlighting their strengths and weaknesses for application in food commodities analysis.

Before introducing and shaping electrochemical chemosensors and biosensors, we would like to highlight some considerations and comments about chitosan, evidencing its functional and structural properties which made it attractive for the preparation of electrochemical chemosensors and biosensors.

\section{Chitosan: structural and functional properties}

Chitosan is a natural polycationic linear polysaccharide and it is one of the most important derivative products of chitin. The main sources of chitin are many types of animals living in terrestrial, marine, and freshwater ecosystems; in particular, chitin has been extracted from the exoskeletons of arthropods (crustaceans, arachnids, and insects), from the crustacean shells of shrimp and prawns, and from beaks of cephalopods. Chitosan also exists in some microorganisms, as in the cell walls of fungi, providing support to the cellular structure and maintaining the cells shape. It is the second most abundant natural polysaccharide just after cellulose. Usually, chitosan is commercialised and stored in different physical forms such as white powders, flakes, and small beads.

While the majority of natural polysaccharides, e.g., pectin, dextrin, agarose, and carrageenans, are usually either neutral or negatively charged in acidic media, chitosan exhibits cationic features, being positively charged [6]. This property allows chitosan to form easily composites or multilayer structures with other synthetic or natural polymers utilizing electrostatic attraction.

Chitosan can be derived from chitin by means of $\mathrm{N}$-deacetylation method as shown in Figure 1. It is considered as a linear polysaccharide and contains copolymers of Dglucosamine (deacetylated units) and of $\mathrm{N}$-acetyl-D-glucosamine (acetylated units) linked by $\beta(1,4)$ glycosidic bonds $[7,8]$. Based on the degree of deacetylation, chitosan has different characteristics and molecular weights. By different degrees of deacetylation, chitosan can be classified in three categories, as high (>500 kDa), medium (ranging from 50 to $500 \mathrm{kDa})$, and low $(<50 \mathrm{kDa})$ molecular weights [9].

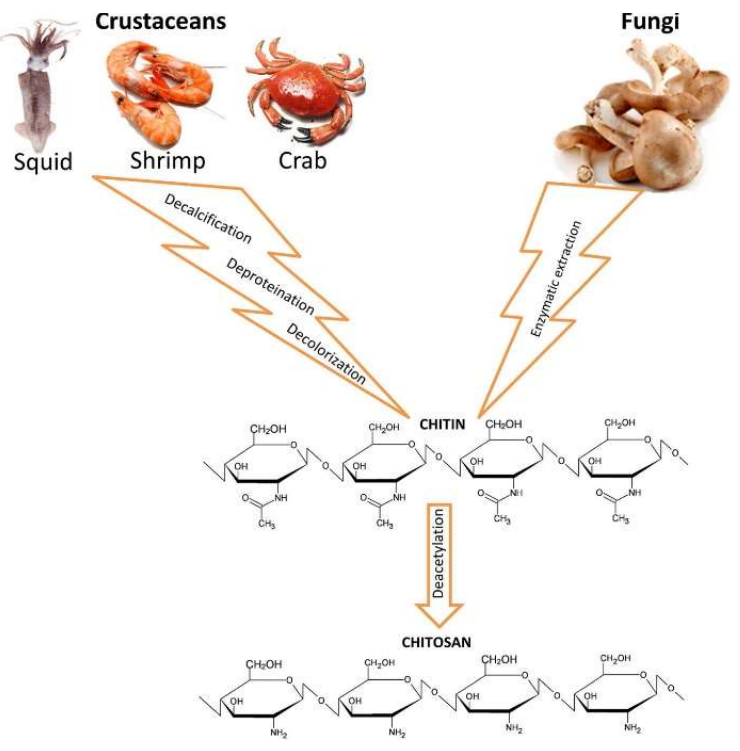


Figure 1. Extraction of chitin and chitosan from different sources. Reprinted with permission from [8]. Copyright 2013 American Chemical Society.

Chitosan presents different special physical properties such as viscosity, and solubility in various media. The solubility of chitosan in aqueous solution can be adapted by modifying the $\mathrm{pH}$ value (usually below 6.5), ionic strength, and the degree of deacetylation. Besides controllable solubility, chitosan exhibits reactive amino and hydroxyl groups in its linear polyglucosamine chains, making it available for appropriate bio/chemical modifications. For example, the primary amino groups in chitosan backbone can provide special chemical moieties suitable for side group attachment, broadening the chitosan applications in bio-composite synthesis [10]. As a result, the chitosan structural and functional properties allow to easily modify the polymer so achieving specific functions [11].

For these characteristics, chitosan ranks close to the top as a suitable substrate material for sensor and biosensor design, owing to its plentiful lateral functional groups for biological/chemical binding, high mechanical rigidity, and area-to-volume ratio. As wellknown and reported in literature [12], a chitosan membrane has a very porous surface topography, with pore size about micrometre.

The porosity of chitosan can increase the surface area of traditional planar sensors and the loading capacity in unit surface area, thus amplifying the output signal response. Additionally, when detecting analytes smaller than bacteria, porous structures of chitosan films have negligible effect on analyte diffusion towards the electrodic surface. Besides the diversity and flexibility of structures and functional groups of chitosan, other important advantages of chitosan are that it is non-toxic, safe for humans and eco-friendly, since the raw materials are biodegradable and renewable. Being nontoxic is important as sensing material component, because it leads to low immunogenicity, which ensures no or little false responses incurred from incompatibility between samples and sensor materials.

\section{Electrochemical chemosensors and biosensors: definitions, techniques, sensing ma- terials}

First of all, we would like to introduce some definitions.

Starting from reference [13], a chemosensor in biology is defined as "a sensory receptor that transduces a chemical signal to an action potential". However, in chemistry, this term is generally associated with the creation of receptors from non-biological chemical entities, so it means that chemical synthesis is used to create artificial receptors, which are therefore generally called "synthetic receptors". In contrast, a biosensor involves the use of receptors based on biological entities, such as peptides, proteins, and nucleic acids.

On the other hand, Wang [14] provided a definition of chemosensor and biosensor starting from different assumptions.

The International Union of Pure and Applied Chemistry defines a chemical sensor as "a device that transforms chemical information, ranging from the concentration of a specific sample component to total composition analysis, into an analytically useful signal" [15]. A typical chemosensor contains two basic functional units: a receptor and a physicochemical transducer, as illustrated in Figure 2. 


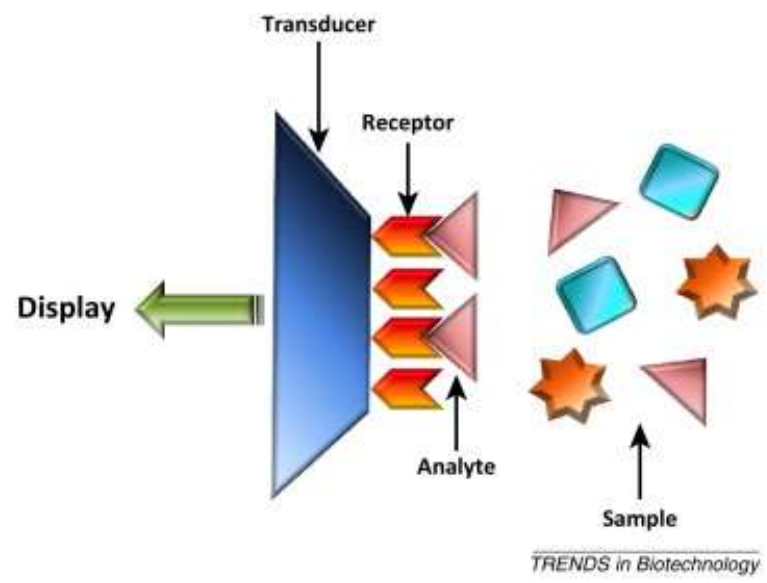

Figure 2. A scheme of a typical chemosensor. Reprinted with permission from [14]. Copyright 2014 Elsevier.

In the receptor part of a sensor, the chemical information is transformed into a form of energy which may be measured by the transducer.

The transducer part is a device capable of transforming the energy carrying the chemical information about the sample into a useful analytical signal. The transducer as such does not show selectivity.

The receptor part of chemical sensors may be based upon various principles:

- physical, where no chemical reaction takes place;

- chemical, in which a chemical reaction involving the analyte gives rise to the analytical signal;

- biochemical, in which a biochemical process is the source of the analytical signal. The corresponding sensors may be regarded as a subgroup of the chemical ones. Such sensors are called biosensors.

The receptor transforms the analyte concentration into a chemical or physical output signal with a defined sensitivity. The main role of the receptor is to provide high selectivity towards the desired analyte in the presence of potentially interfering chemical species.

The transducer is another crucial component of the sensor that serves to convert the signal generated by the receptor-analyte interaction to a readable value. Biosensors can be distinguished based on their receptors, as either catalytic or affinity-based [2, 16-18].

Finally, according to the Wang's definition, a biosensor is a chemosensor with a biological entity as receptor [14]. Both chemosensors and biosensors can be classified according to the type of transducer used as electrochemical, optical, piezoelectric, and calorimetric sensors.

Particularly, in this review we focused on electrochemical chemosensors and biosensors, providing some examples of application to the food analysis.

Electrochemical sensors and biosensors may be classified according to the operating principle of the transducer. In general, electrochemical transducers are able to convert the effect of the electrochemical interaction analyte-electrode into a measurable electrical signal (such as current, voltage, charge, and impedance).

As for all the chemical sensors, the critical parameters of all the electrochemical sensors are sensitivity, detection limit, dynamic range, selectivity, linearity, response time, and stability [19].

Several electrochemical methods have been employed for the food analysis [2]: an electrochemical reaction can generate different measurable data, depending on the measurable electrical signal produced and consequently on the electrochemical technique adopted. In fact, a current can be generated, and in this case, the corresponding electrochemical techniques are the amperometric ones. Alternatively, a potential can be 
measured and/or controlled, and in this case, the corresponding electrochemical techniques are the potentiometric ones. Finally, the electrochemical techniques involving measurements of impedance at the electrode/solution interface are included in the electrochemical impedance spectroscopy (EIS) method [2].

Briefly, we propose an overview of the best known and used electrochemical techniques.

Electrochemical impedance spectroscopy (EIS) is an effective technique for detecting the interaction between (bio)receptor onto the electrode surface and the analyte by testing the electrode/electrolyte interface and following the change in the impedance of the electrode/solution interface [2].

In an amperometric sensor, the current produced at the working electrode is measured when a certain potential is applied. The current so produced is directly related to the oxidation or reduction process of the target molecule after its interaction with the electrode in proportion to the analyte concentration.

Generally, the widest used amperometric techniques are constant potential amperometry and chronoamperometry.

Constant potential amperometry (CPA) is an electrochemical technique in which the current is measured, while the potential difference between the sensing and the reference electrodes is held at a constant value sufficient to oxidize or reduce the analyte. This potential value is generally evaluated from cyclic and/or linear voltammetry experiments.

Chronoamperometry (CA) is a potentiostatic technique, where the current is recorded as a time function, and it is useful to determine the concentration of the analyte, once its identity is known using other techniques, such as voltammetry, chromatography and/or other separation techniques.

Voltammetry belongs to the class of the amperometric techniques because the current produced from an electrochemical reaction is measured whilst varying the potential window. Since there are many ways to vary the potential, we can consider many voltammetric techniques. Among others, the most common and employed are the following: cyclic voltammetry (CV), linear sweep voltammetry (LSV), differential pulse voltammetry (DPV), and square wave voltammetry (SWV). CV and LSV are the voltammetric techniques employed to study the electrochemical behavior of an electroactive molecule. DPV and SWV can be classified as pulse voltammetric techniques. They can be used to study the redox properties of extremely small amounts of electroactive compounds for several reasons, but principally: (1) in these measurements, the effect of the charging current can be minimized, so higher sensitivity is achieved and (2) only faradaic current is extracted, so electrode reactions can be analyzed more precisely.

All the above-mentioned techniques have been widely employed in the development of electrochemical sensors for different application fields.

For more details about theories, underlying the different electrochemical approaches used for electrochemical chemosensors and biosensors, several books and reviews in the literature are well-known [19-25].

The transducer is the most important component of a sensor, because it directly determines the sensor performances, such as sensitivity and response time. The chemical reaction occurring in the sensing layer near the electrode surface is transformed into an electrochemical signal. The rate and the quality of signal production are directly related to the surface properties of the electrode, the rate of electron transfer, and mass transfer. Thus, selecting electrode material highly affects the rate of electron transfer in electrochemical sensors and biosensors. The most common types of electrodes and sensing materials used for chitosan-based electrochemical chemosensors and biosensors concerning the food analysis are reported below.

First of all, we must stress the relevance of the nanomaterials introduction in the sensing area. In fact, they exhibit highly tunable size- and shape-dependent chemical and physical properties which can be exploited in particular for fabrication of chemosensors and biosensors $[5,26]$. Nanomaterials also show unique surface chemistry, thermal and electrical properties, and high surface area per unit mass. These properties can help to 
improve the sensors performances. The recent years have witnessed many successful reports on the synthesis of a broad range of nanomaterials with different conducive structures, compositions, and properties for use in fabrication of different sensors.

Nanomaterials, nanoparticles, nanocomposites, and nanostructures, used both as electrode modifiers and for electrochemical signal amplification, play an important role in developing electrochemical (bio)sensors for food safety with improved performance in terms of stability and sensitivity

Carbon has been recognized as one of the most common electrode materials used in electrochemical (bio)sensing area. The most common forms of carbon used as electrode materials and/or as electrode modifiers are carbon paste, glassy carbon, carbon nanotubes, graphene, and carbon black. All these carbon materials are cheaper than noble metals. [2, 5]

Carbon paste is made of graphite powder and an organic binder, immiscible with water, and it is useful in insulating graphite from aqueous solutions. This carbon-based electrode presents several advantages, such as low cost, low background current, regenerability, and various operating potentials. Chitosan as other molecules can be easily incorporated into the carbon paste for sensing applications. Similarly, glassy carbon electrodes have also been employed for electrochemical sensors using ad hoc modifications. However, apart from their high cost, glassy carbon electrodes need an accurate pretreatment procedure, constraining their use in many electrochemical applications. On the other hand, they can be easily modified with chitosan, so the critical issue of the pretreatment is considered negligible in many cases. In our opinion, this criticality is a real problem for the possible sensor commercialization.

Carbon nanotubes (CNTs) present several properties associated with their structure, functionality, morphology, and flexibility; they can be classified as single-walled nanotubes (SWNTs), double-walled nanotubes (DWNTs), and multi-walled nanotubes (MWNTs), depending on the number of graphite layers. [27] Functionalized CNTs have been used in several application fields. The chemical functionalities for their application in bio-sensing can easily be designed and tuned through tubular structure modification.

Graphene is one of the most applied nanomaterials in the sensing area. Different graphene-based materials have been produced (e.g., electrochemically, and chemically modified graphene) using many procedures [28]. Graphene shows properties, such as high conductivity, speeding up electron transfer, and a large surface area, very similar indeed to the corresponding properties of CNTS, so it is considered a good candidate for assembling (bio)sensors to determine several target molecules.

Graphene oxide (GO) is hydrophilic and can be dispersed in water solution because of the presence of hydrophilic functional groups $(\mathrm{OH}, \mathrm{COOH}$ and epoxides). On the other hand, GO has a conductivity lower than graphene, so reduced GO (rGO) is more employed as the electrode modifier in the electrochemical biosensing area [28-29].

Last but not least, we would like to introduce an old and low-cost carbon-based nanomaterial, i.e., carbon black (CB). It exhibits large surface area, excellent electrical conductivity, dispersible in solvents, possible easy functionalisation, and presents several defect sites very useful for further functionalization and/or binding sites and fast electron transfer kinetics [30-33].

The peculiar properties of gold (e.g., biocompatibility, stability, and conductivity) have promoted its use as electrode in electrochemistry. The gold electrode sensitivity and functionality can be enhanced by modifying the surface, introducing suitable molecules and polymers such as chitosan.

In addition, gold nanomaterials were employed in the electrochemical (bio)sensing area not only for their high conductivity and compatibility but also for their high surface to volume ratio [34-38].

Recently, nanoporous gold (NPG) with unique properties has received increasing interest and attention in electrochemical catalysis and electrochemical sensor design [39].

Because of its geometrical features, such as irregularity, large roughness, and high porosity, which allow more active sites on the electrode surface and increased probability 
for charge transfer between molecules and electrode surface and the resulting nanostructure, NPG was turned out to be capable of sensing without enzyme by directly oxidizing small molecules, such as dopamine, ascorbic acid, hydrazine, and several environmental pollutants.

Finally, nonconventional sensing platforms, such as paper and/or screen-printed electrodes (SPE) frequently modified with different nanomaterials and/or nanostructures, are employed in assembling electrochemical chemosensors and biosensors.

Screen-printing technology offers several advantages for assembling electrochemical biosensors, including a wide range of geometries, mass production, disposability, and portability [40]. These properties are very important for commercializing biosensors.

Recent developments in the fabrication of screen-printed electrodes (SPEs) were the topic not only of numerous original research papers but also of interesting reviews [41, 42], analysing the selection of support material, ink composition, and methods of surface modification or functionalization. Finally, in all the reviews mentioned above, methods of obtaining well defined geometries and microelectrode arrays are discussed and compared for assembling smart electrochemical biosensors.

\section{Applications to food safety}

In this section, several examples of electrochemical chemosensors and biosensors are reported, evidencing different approaches for assembling smart chitosan-based sensing platforms and applications to detect different analytical targets involved in the food analysis. Before illustrating the several applications, we would like to introduce the different typologies of chitosan-based sensing platforms.

As reported in section 2, chitosan is a functional material showing good adhesion, film-forming ability, and biocompatibility, so it is considered a good material to develop sensing platforms.

On the other hand, chitosan is a non-conducting biopolymer, for this reason it is generally combined with nanomaterials as well as with conducting polymers to improve its conductivity.

Moreover, this biopolymer presents on its backbone several hydroxyl (OH) and amine $\left(\mathrm{NH}_{2}\right)$ groups, so it results a candidate for the immobilization of biomolecules. In fact, these reactive groups can be rapidly coupled with various types of biomolecules, such as DNA, enzymes, and antibody/antigen, using covalent, electrostatic, or entrapment immobilizing approaches.

In particular, hydrogels of chitosan are largely applied for the entrapment immobilization. Hydrogels are a class of polymeric materials with a three-dimensional network structure, possessing a marginal amount of water. It can be also defined as a substance in which a liquid is dispersed microscopically inside a solid network [43]. As hydrogels are highly compatible with most of biological molecules and substrates, they have gained attraction in sensing area. To date, research activities using hydrogels as a major component in sensor systems have been extensively performed [43].

Chitosan has been also employed as molecular imprinted polymer (MIP). As reported in literature [44], MIP is defined as an artificial recognition material whose size and shape of the corresponding binding sites are complementary to the template molecules for the specific recognition. To generate a MIP with tailored cavities, a monomer is polymerized in the presence of the target molecule and a crosslinking agent leading to the formation of a highly cross-linked functional monomer/template complex. Cavities tailored to the target molecule are then obtained after extracting the template from the polymer. Template/monomer and crosslinking agent/monomer ratios play an important role in the synthesis of MIPs improving their efficiency. Furthermore, because of their high affinity and selectivity towards target molecules, they can be considered comparable to the natural receptors [44]. Finally, thanks to the chitosan biocompatibility and film- 
forming capability, its MIPs are widely employed as receptors for assembling electrochemical chemosensors.

In the following subsections, recent examples of electrochemical chitosan-based chemosensors and biosensors applied to detect different analytical targets such as some phenolic antioxidants, caffeine, bacteria, contaminants, toxins, and pesticides were illustrated and discussed.

\subsection{Phenolic antioxidants}

Natural antioxidants are species of great interest in many areas, as food chemistry, health care and clinical applications. They have beneficial effects on human health and could play an important role in the prevention and treatment of many diseases and to protect from oxidative stress $[5,45,46]$.

Among the natural antioxidants found in fruits and plants, hydroxycinnamic acids (HAs) are very important and present in all parts of the fruit and/or plant [47]. Undoubtedly, these compounds in food provide several advantages for their well-known health benefits, for their technological role, and marketing. Extensive electrochemical studies have been performed to investigate the redox properties of HAs and consequently to define an analytical strategy for their analysis and detection [48].

At present, as for other classes of antioxidants, the analysis of HAs and phenolic antioxidants is usually carried out using chromatographic techniques [49-51], requiring at least sophisticated equipment and laborious analytical procedures, but the use of electrochemical methods for analytical purposes is receiving increasing interest [48, 52]. Interesting examples of electrochemical chitosan-based sensors and biosensors are reported in table 1.

Table 1. Recent examples of electrochemical chitosan-based sensors for HAs detection.

\begin{tabular}{ccccccc}
\hline Electrode & (Bio)Sensor Format & $\begin{array}{c}\text { Electro- } \\
\text { chemical } \\
\text { Technique }\end{array}$ & Analyte/Sample & L.R. & LOD & References \\
\hline AuE & $\begin{array}{c}\text { Electrochemical sensor based on } \\
\text { AuNPs /CHI nanocomposite }\end{array}$ & DPV & $\begin{array}{c}\text { Caffeic acid/red } \\
\text { and white wines }\end{array}$ & $\begin{array}{c}5.00 \times 10^{-8} / \\
2.00 \times 10^{-3} \mathrm{M}\end{array}$ & $2.50 \times 10^{-8} \mathrm{M}$ & {$[53,54]$} \\
\hline AuE & $\begin{array}{c}\text { Electrochemical biosensor based on } \\
\text { Laccase enzyme immobilized by en- } \\
\text { trapment in MWCNTs/CHI nano- } \\
\text { composite }\end{array}$ & CA & $\begin{array}{c}\text { Rosmarinic } \\
\text { acid/Mint and Sal- } \\
\text { via officinalis ex- } \\
\text { tracts }\end{array}$ & $\begin{array}{c}9.1 \times 10^{-7} / \\
1.21 \times 10^{-5} \mathrm{M}\end{array}$ & $2.33 \times 10^{-7} \mathrm{M}$ & {$[56]$} \\
\hline CPE & $\begin{array}{c}\text { Electrochemical sensor based on CPE } \\
\text { modified with MWCNTs and chi- } \\
\text { tosan and covered with DNA }\end{array}$ & SWSV & $\begin{array}{c}\text { Rosmarinic } \\
\text { acid/Rosmarinus of- } \\
\text { ficinalis extracts }\end{array}$ & $0.040-1.50 \mu \mathrm{M}$ & $0.014 \mu \mathrm{M}$ & {$[63]$} \\
\hline
\end{tabular}

Abbreviations: AuE: gold electrode; AuNPs: gold nanoparticles; CA: chronoamperometry; CHI: chitosan; CPE: carbon paste electrode; DPV: differential pulse voltammetry; MWCNTs: multi-walled carbon nanotubes; SWSV: square-wave stripping voltammetry.

Recently, electrodes modified with nanocomposite films were successfully used for the analysis of antioxidants, such as caffeic acid, in complex matrices [53, 54].

Caffeic acid (CA, 3,4-dihydroxycinnamic acid, chemical structure in Figure 3) is well known as a phenolic antioxidant. CA is present in wines, coffee, olive oil, as well as in some vegetables and fruits $[47,48,52]$. 


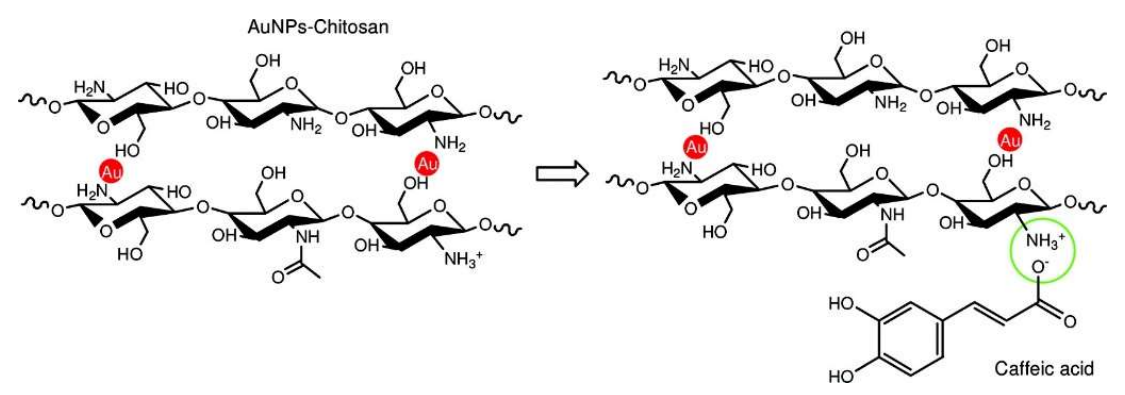

Figure 3. Schematic representation of the interaction between AuNPs/chitosan nanocomposite and caffeic acid. Reprinted with permission from [53]. Copyright 2012, American Chemical Society.

The nanocomposite films consist of gold nanoparticles (AuNPs) embedded into chitosan; it is clear that the nanoparticles increase the conductivity of the biopolymer.

Taking advantage of the peculiar sensing performance of the nanocomposite, an analytical method based on differential pulse voltammetry for the determination of the polyphenol index in wines was proposed.

In this approach, colloidal gold nanoparticles (AuNPs) stabilized into a chitosan matrix were prepared using a green route. The synthesis was carried out by reducing AuIII to $\mathrm{Au0}$ in an aqueous solution of chitosan and different organic acids. It has been demonstrated that by varying the nature of the acid it is possible to tune the reduction rate of the gold precursor $\left(\mathrm{HAuCl}_{4}\right)$ and to modify the morphology of the resulting metal nanoparticles. The use of chitosan enables the simultaneous synthesis and surface modification of AuNPs in one pot. Because of the excellent film-forming capability of this polymer, AuNPs-chitosan solutions were used to obtain hybrid nanocomposite films that combine highly conductive AuNPs with many organic functional groups.

The nanostructure and surface functional groups of AuNPs-chitosan modified electrodes have also a key role. In particular, the formation of a collaborative network with interconnected metal nanoparticles in chitosan film significantly affects the electron transfer properties, whereas the surface functional groups can promote the interaction with the antioxidant, as shown in Figure 3.

An overview of the behaviour of catechols, hydroxycinnamic acids, and flavonoids derivatives at different AuNPs-chitosan modified electrodes has been illustrated by $\mathrm{Cu}$ rulli and co-workers [55].

A better response was observed for molecules with two hydroxyl groups in ortho position of the catechol ring, with a peculiar molecular symmetry (i.e., rosmarinic acid) and with a low steric hindrance, in particular for caffeic acid, chlorogenic acid, and rosmarinic acid. Moreover, the interaction with the antioxidants was also affected by the functional groups at modified electrode surface and the size and distribution of AuNPs into the polymeric matrix. The understanding of the parameters affecting the electrochemical behaviour of analytes at modified electrodes is a key issue and could significantly promote the design of highly efficient sensors.

Au-chitosan nanocomposites are successfully proposed as sensitive and selective electrochemical sensors for the determination of caffeic acid, by means of Differential Pulse Voltammetry. A linear response was obtained over a wide range of concentration from $5.00 \times 10^{-8} \mathrm{M}$ to $2.00 \times 10^{-3} \mathrm{M}$, and the limit of detection was $2.50 \times 10^{-8} \mathrm{M}$. Moreover, further analyses have demonstrated that a high selectivity toward caffeic acid can be achieved without interference from catechin or ascorbic acid (flavonoid and nonphenolic antioxidants, respectively). The quantification of the caffeic acid in red and white wines was also accomplished by standard addition method. The only sample treatment required in all cases consisted of an appropriate dilution with the supporting electrolyte solution, 
and the obtained results are in accordance with amounts reported in the literature for commercial samples [53, 54].

Diaconu and co-workers [56] have proposed an electrochemical biosensor based on Laccase enzyme from Trametes versicolor for total polyphenolic content evaluation from in vitro cultivated plants: Salvia officinalis and Mentha piperita. The enzyme immobilization was carried out by entrapment into the nanocomposite film during electrodeposition process from multiwall carbon nanotubes (MWCNTs)-chitosan (CHI) solution. As introduced in section 3, chitosan has been widely used as matrix for enzyme immobilization through ionic or covalent crosslinking, dip-coating, or the electrodeposition processes [57-60]. Electrochemical deposition of chitosan has been reported as an effective method for enzyme immobilization and formation of chitosan film with controllable thickness. During electrodeposition, compounds such as redox mediators [61] and/or nanomaterials e.g., carbon nanotubes [57-60], can be incorporated into the chitosan film, leading to bio-nanocomposites with enhanced electrical conductivity. It was proved by means of FTIR investigation that the Laccase enzyme retains its conformational specificity, so the entrapment in nanocomposite preserves the enzyme good functionality as biocatalyst. In this work, the optimization of the biosensor was carried out with respect to rosmarinic acid as Laccase specific substrate because it is one of the main components of Salvia [62] and Mint extracts, and so the total polyphenolic content from real samples has been expressed in equivalent rosmarinic acid. Under optimized conditions and by means of amperometry, a limit of detection $2.33 \times 10^{-7} \mathrm{M}$ and a linear range from $9.10 \times 10^{-7}$ to $1.21 \times 10^{-5} \mathrm{M}$ were obtained. It should be underlined that the value of the apparent Michaelis-Menten constant ( $\mathrm{K}_{\text {mapp }}$ ) $1.8 \times 10^{-4} \mathrm{M}$ is comparable with that one reported in literature [56], indicating that $\mathrm{CH}-$ MWCNT nanocomposite layer provides a friendly environment for enzyme immobilization, preserving its catalytic specificity. Finally, the biosensor was applied to determine the total polyphenolic content (TPC) of real samples (S. officinalis and M. piperita extracts), and the obtained results were expressed in equivalent rosmarinic acid, but they were not validated from an independent method.

An electrochemical sensor based on a chitosan/carbon nanotube composite-modified carbon paste electrode covered with DNA has been prepared for the detection of rosmarinic acid (RA) [63]. More precisely, the bulk of a carbon paste electrode was modified with carbon nanotubes and chitosan and then the surface of the obtained electrode was covered with DNA. Chitosan can form a tight complex with the polyanionic phosphodiester backbones of DNA, which made the immobilization very stable [64]. The sensing approach was based on the interaction between RA from solution and DNA immobilized on the electrode surface; consequently, this strong interaction gives rise to an accumulation of rosmarinic acid on the electrode surface resulting in an efficient preconcentration leading to high sensitivity of the sensor for rosmarinic acid determination.

Rosmarinic acid (RA, chemical structure in Figure 4) is an ester of caffeic acid [65]. It is also one of the natural antioxidants acting as an antiseptic, antiviral, antibacterial and anti-inflammatory agent. RA is an important and major secondary metabolite present in some plants, and applied also in various fields such as medicine, cosmetics, and food industry.<smiles>O=C(/C=C/c1ccc(O)c(O)c1)O[C@@H](Cc1ccc(O)c(O)c1)C(=O)O</smiles>

Figure 4. Chemical structure of rosmarinic acid [65]. 
Several experimental parameters affecting the sensor response were optimized. Under the optimized conditions and using square wave stripping voltammetry as analytical technique, a linear concentration range of $0.040-1.5 \mu \mathrm{M}$ with a detection limit of $0.014 \mu \mathrm{M}$ was obtained. The proposed method was successfully applied to the analysis of a rosemary extract. The obtained data were in good agreement with those ones obtained from HPLC analysis with a recovery ranging from 103 to $98 \%$.

\subsection{Caffeine}

Caffeine (CAF, chemical structure in Figure 5 ) is a natural alkaloid, distributed in seeds, nuts, or leaves of a number of plants, mainly coffee, cocoa, tea, and it is the most widely consumed psychoactive substance in human dietary.<smiles>Cn1c(=O)c2c(ncn2C)n(C)c1=O</smiles>

Figure 5. Chemical structure of caffeine. Reprinted with permission from [69]. Copyright 2017 Elsevier.

Recently, an antioxidant activity has been suggested for CAF, showing protective effects against oxidative stress[66-69]. The presence of CAF in many beverages and drug formulations of worldwide economic importance [69] makes it an analyte of great interest. Electrochemical determination of CAF on different electrode materials, ranging from bare and miscellaneously modified carbon-based electrodes to nanomaterials-based electrodes, has been also reported in literature [5]. In this review, we focused our attention on chitosan-based electrochemical sensors and interesting examples are reported in table 2.

Table 2. Recent examples of electrochemical chitosan-based sensors for caffeine detection.

\begin{tabular}{ccccccc}
\hline \multirow{2}{*}{ Electrode } & Sensor Format & $\begin{array}{c}\text { Electrochemical } \\
\text { Technique }\end{array}$ & Analyte/Sample & L.R. & LOD & References \\
\hline \multirow{2}{*}{ GCE } & $\begin{array}{c}\text { Electrochemical sensor based on } \\
\text { AuNps/CHI/IL/rGO nanocomposite }\end{array}$ & DPV & $\begin{array}{c}\text { Caffeine/tea, } \\
\text { energy drink }\end{array}$ & $\begin{array}{c}2.50 \times 10^{-8} / \\
2.49 \times 10^{-6} \mathrm{M}\end{array}$ & $4.42 \times 10^{-9} \mathrm{M}$ & {$[70]$} \\
\hline \multirow{2}{*}{$\mathrm{AuE}$} & $\begin{array}{c}\text { Electrochemical sensor based on } \\
\text { AuNPs /CHI nanocomposite }\end{array}$ & DPV & $\begin{array}{c}\text { Caffeine/Coca } \\
\text { Cola, Pepsi Cola, } \\
\text { energy drink, } \\
\text { green tea, tea }\end{array}$ & $\begin{array}{c}2.00 \times 10^{-6} / \\
5.00 \times 10^{-2} \mathrm{M}\end{array}$ & $1.00 \times 10^{-6} \mathrm{M}$ & {$[69]$} \\
\hline
\end{tabular}

Abbreviations: AuE: gold electrode; AuNPs: gold nanoparticles; CA: chronoamperometry; CHI: chitosan;; DPV: differential pulse voltammetry; GCE: glassy carbon electrode; IL: ionic liquid; rGO: reduced graphene oxide

As first example, we would like to introduce a sensor for CAF and theophylline (TP) detection based on a nanohybrid film containing anisotropic gold nanoparticles (AuNPs) chitosan and an ionic liquid (IL) such as 1-butyl-3-methylimidazoliumtetrafluoroborate, $[\mathrm{BMIM}]\left[\mathrm{BF}_{4}\right][70]$. The nanocomposite has been drop-casted on a glassy carbon electrode (GCE) coated with reduced graphene oxide (rGO). We remind that theophylline can be used for treating respiratory diseases, but it also can cause nausea, diarrhea, arrhythmias, etc. [70]. Consequently, its use must be monitored to avoid toxicity.

Anisotropic AuNPs were prepared by reducing $\mathrm{HAuCl}_{4}$ in $\mathrm{CHI}-\mathrm{IL}$ aqueous solution. The resulting solution was directly casted on rGO modified GCE) to form a nanocomposite film. This is the first time that IL and CHI have a controlling and shaping role in the synthesis of anisotropic AuNPs. In fact, it has to be underlined that if the reaction 
was performed only in $\mathrm{CH}$ aqueous solution, anisotropic AuNPs were obtained, and the diameters were ranging from 30 to $50 \mathrm{~nm}$, indicating that the $\mathrm{CHI}$ is a crucial factor to synthesize AuNPs with an anisotropic structure. When the reaction was performed in CHI-IL aqueous solution, the diameter of major nanoparticles was ranging from 5 to 30 $\mathrm{nm}$, which means that IL plays an important role to control the dimensions/diameters of AuNPs. The hybrid film had a three-dimensional structure, and small anisotropic AuNPs were well distributed in it. All the factors influencing the sensor performances were investigated, including the ingredients of the hybrid film, the concentrations of rGO, $\mathrm{HAuCl}_{4}$, and IL, and the buffer solution $\mathrm{pH}$.

Under the optimized conditions, the linear response ranges were $2.50 \times 10^{-8}-2.10 \times 10^{-6}$ $\mathrm{M}$ and $2.50 \times 10^{-8}-2.49 \times 10^{-6} \mathrm{M}$ for TP and CAF, respectively. The detection limits were $1.32 \mathrm{x}$ $10^{-9} \mathrm{M}$ and $4.42 \times 10^{-9} \mathrm{M}$, respectively. The electrochemical sensor showed good reproducibility, stability, and selectivity, and it has been applied to the determination of TP and CAF in real samples, including tea, energy drink and pharmaceutics. The obtained results were in agreement with those obtained with HPLC. The recoveries for the TP and CAF standards added are $97 \%$ to $107 \%$ and $98 \%$ to $104 \%$, respectively.

Curulli group developed a simple and selective method for the determination of caffeine also in complex matrix at a gold electrode modified with gold nanoparticles (AuNPs) synthetized in a chitosan matrix in the presence of oxalic acid [69].

The electrochemical behaviour of caffeine at both gold bare and gold electrode modified with AuNPs was carried out in acidic medium by cyclic voltammetry (CV), differential pulse voltammetry (DPV) and electrochemical impedance spectroscopy (EIS). Electrochemical parameters were optimized to improve the electrochemical response to caffeine. The most satisfactory result was obtained using a gold electrode modified with AuNPs synthetized in a chitosan matrix in the presence of oxalic acid (AuOA-CH), in aqueous solution containing $\mathrm{HClO}_{4} 0.4 \mathrm{M}$ as supporting electrolyte.

The better performance of AuOA-CHI modified electrode can be explained with a better interconnection between AuNPs and caffeine: the 3D network of AuNps in the chitosan film can be considered responsible for a more efficient electron transfer, whereas the functional groups on the chitosan backbone are able to interact effectively with CAF as scavengers.

The performance of the sensor was then evaluated in terms of linearity range $(2.0 \mathrm{x}$ $\left.10^{-6}-5.0 \times 10^{-2} \mathrm{M}\right)$, operational and storage stability, reproducibility, limit of detection $\left(1.0 \times 10^{-6} \mathrm{M}\right)$ and response to a series of interfering compounds such as ascorbic acid, citric acid, gallic acid, caffeic acid, ferulic acid, chlorogenic acid, glucose, catechin and epicatechin. The sensor was then successfully applied to determine the caffeine content in commercial beverages and the results were in agreement with those obtained with HPLCPDA as an independent method and with those declared from manufacturers.

\subsection{Pathogenic bacteria}

Bacteria are the most common cause of foodborne diseases in the world [71]. Due to the potential threat of foodborne pathogens and the fact that the infective dose of some of them is low, pathogenic cells of some species must be totally absent from food. For example, see the Salmonella case [72].

Considering all these critical issues, developing accurate, simple, rapid, low-cost, and possibly portable devices able to make point-of-care analyses is mandatory.

There are many kinds of pathogens producing toxins causing foodborne diseases [73]; among them Escherichia coli, Salmonella, and Listeria monocytogenes are common and recent examples of the electrochemical chitosan-based (bio)sensors, included in table 3 , have been reported and discussed.

Table 3. Recent examples of electrochemical chitosan-based (bio)sensors for pathogenic bacteria detection 


\begin{tabular}{|c|c|c|c|c|c|c|}
\hline Electrode & (Bio)Sensor Format & $\begin{array}{c}\text { Electro- } \\
\text { chemical } \\
\text { Technique }\end{array}$ & Analyte/Sample & L.R. & LOD & References \\
\hline GCE & $\begin{array}{c}\text { Electrochemical immunosensor based } \\
\text { on high-density gold nanoparticles } \\
\text { (AuNPs), dispersed in chitosan (CHI) } \\
\text { hydrogel, and modified glassy car- } \\
\text { bon electrode (GCE) }\end{array}$ & DPV & $\begin{array}{c}\text { Salmonella/milk, } \\
\text { water }\end{array}$ & $\begin{array}{c}10-10^{5} \\
\text { CFU mL }{ }^{-1}\end{array}$ & $5 \mathrm{CFU} \mathrm{mL}^{-1}$ & {$[74]$} \\
\hline GCE & $\begin{array}{c}\text { Electrochemical aptasensor } \\
\text { developed using electrochemically } \\
\text { reduced graphene-oxide-chitosan } \\
\text { (rGO-CHI) composite deposited onto } \\
\text { GCE }\end{array}$ & DPV & Salmonella/chicken & $\begin{array}{c}10-10^{6} \\
\text { CFU mL-1 }\end{array}$ & $10 \mathrm{CFU} \mathrm{mL} \mathrm{m}^{-1}$ & [77] \\
\hline PGE & $\begin{array}{c}\text { Electrochemical immunosensor based } \\
\text { on the PPy/AuNP/MWCNT/CHI hy- } \\
\text { brid nanocomposite modified pencil } \\
\text { graphite electrode (PGE) }\end{array}$ & $\begin{array}{l}\text { Amperome- } \\
\text { try }\end{array}$ & $\begin{array}{l}\text { E. coli/no real sam- } \\
\text { ples }\end{array}$ & $\begin{array}{c}30-30^{6} \\
\mathrm{CFU} \mathrm{mL} \mathrm{m}^{-1}\end{array}$ & $30 \mathrm{CFU} \mathrm{mL}^{-1}$ & {$[80]$} \\
\hline $\mathrm{Pt} / \mathrm{Ir}$ & $\begin{array}{l}\text { Impedimetric label-free aptasensor } \\
\text { based on Pt/Ir electrode modified } \\
\text { with graphene-nanoplatinum "sand- } \\
\text { wich" transducer layer and rGO sus- } \\
\text { pension }\end{array}$ & EIS & $\begin{array}{l}\text { Listeria monocyto- } \\
\text { genes/vegetal broth }\end{array}$ & $\begin{array}{c}9-10^{7} \\
\mathrm{CFU} \mathrm{mL} \mathrm{mL}^{-1}\end{array}$ & $3 \mathrm{CFU} \mathrm{mL}^{-1}$ & [81] \\
\hline GCE & $\begin{array}{c}\text { Horseradish peroxidase labelled } \\
\text { sandwich immunosensor, based on a } \\
\text { nanocomposite including gold nano- } \\
\text { particles, chitosan, and IL }\end{array}$ & $\mathrm{CV}$ & $\begin{array}{c}\text { Lactobacillus } \\
\text { brevis/beer }\end{array}$ & $\begin{array}{c}10^{4}-10^{9} \\
\text { CFU mL-1 }\end{array}$ & $10^{3} \mathrm{CFU} \mathrm{mL} \mathrm{m}^{-1}$ & [82] \\
\hline \multicolumn{7}{|c|}{$\begin{array}{l}\text { Abbreviations: AuE: gold electrode; AuNPs: gold nanoparticles; CA: chronoamperometry; CHI: chitosan; CPE: carbon } \\
\text { paste electrode; CV: cyclic voltammetry; DPV: differential pulse voltammetry; EIS: electrochemical impedance } \\
\text { spectroscopy: IL: ionic liquid; MWCNTs: multi-walled carbon nanotubes; PGE: pencil graphite electrode; rGO: reduced } \\
\text { graphene oxide. }\end{array}$} \\
\hline
\end{tabular}

As first example, we have to introduce an electrochemical immunosensor for detection of Salmonella, developed using gold nanoparticles (AuNPs) well distributed in chitosan hydrogel and a modified glassy carbon electrode [74]. As chitosan solution is protonated and positively charged, AuNPs can be easily adsorbed onto the surfaces of chitosan and form a biocompatible film. However, the electron transfer between the electrode and biomolecules is prevented because of the low conductivity of chitosan film [75]. Consequently, for guaranteeing an effective electron-transfer, chitosan and AuNPs have been mixed together, for improving the performance of the composite film. AuNPs were well dispersed in the biopolymer film, and then the nanocomposite was casted on the electrode surface. It has been demonstrated that a chitosan film can be oxidized in $\mathrm{NaCl}$ solution so forming reactive carbonyl groups capable of reacting with proteins [76]. In the paper, the anodic oxidation of the immobilized composite film was performed in a conjugation buffer $(0.1 \mathrm{M} \mathrm{NaCl}$ and $0.1 \mathrm{M}$ phosphate buffer, $\mathrm{pH} 7)$ and by applying $0.9 \mathrm{~V}$ to the GCE electrode for $20 \mathrm{~s}$. Considering the biocompatibility of chitosan and AuNPs, the film can provide a good interface and microenvironment for the conjugation of proteins, so this process was carried out by incubating the activated films with Salmonella antibody solution. After incubating the modified electrode in Salmonella suspension and horseradish peroxidase (HRP) conjugated secondary antibody (Ab2) solution, a sandwich electrochemical immunosensor was obtained. The immunosensor showed a linear range from 10 to $10^{5} \mathrm{CFU} \mathrm{mL} \mathrm{m}^{-1}$ with a low detection limit of $5 \mathrm{CFU} \mathrm{mL}^{-1}$. Furthermore, the sensor's 
performances in real-to-life conditions were tested by analyzing tap water and milk samples containing Salmonella. The results were compared and validated with those obtained by the plate counting method, indicating that the immunosensor was suitable for food safety analysis.

An electrochemical aptasensor [77] was assembled employing a thiol functionalized aptamer-immobilized onto the electrochemically reduced graphene-oxide-chitosan composite (rGO-CHI) as a conductive platform for the Salmonella detection

The composite rGO-CHI was prepared by mixing together the biopolymer and rGO We remind that the characteristic chemical inertness, high current density, and hydrophobicity at the nanometre level of reduced graphene oxide (rGO) make it a conductive platform for the development of a (bio)sensor [78]. rGO exhibits a wide electrochemical potential and minimal charge transfer resistance compared to graphite and glassy carbon. The combination of rGO with chitosan $(\mathrm{CH})$ further enhances the properties of rGO by producing a suitable microenvironment for sensors, providing a facile surface modification [78]. In literature it is well known that [79] the coupling of these two materials increases mechanical and tensile properties and produces a strengthened matrix for coating and/or immobilizing on appropriate molecules and systems. In this case, rGO-CHI composite formed a conductive nanocomposite $\left(4.5 \mathrm{~A} \mathrm{~m}^{-2}\right)$, stable to host the immobilized and modified aptamer without degrading.

In fact, a thiol-functionalized aptamer specific for a surface membrane protein of Salmonella was selected as the biorecognition element and was immobilized on rGO-CHI using glutaraldehyde as crosslinker. The aptasensor against Salmonella has been electrochemically characterized and tested using cyclic voltammetry and differential pulse voltammetry techniques. The developed aptasensor is specific to Salmonella and could distinguish between Salmonella enterica cells and non-Salmonella bacteria. The aptasensor exhib-

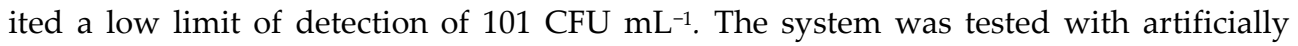
spiked raw chicken samples and results were consistent with the sensitivity results obtained using pure cultures.

An electrochemical immunosensor for the common food pathogen Escherichia coli was developed, based on a hybrid bionanocomposite including chitosan, polypyrrole, gold nanoparticles and multiwalled carbon nanotubes (PPy/AuNPs/MWCNT/CHI) [80]. The nanohybrid composite was used to modify a pencil graphite electrode (PGE) and an anti-E. coli monoclonal antibody was immobilized on it.

Considering the ingredients of the nanocomposite, AuNps and MWCNTs have high surface area, unique electrical and mechanical properties and promote electron transfer between electrochemically active compounds and electrodes. In addition, chitosan was adopted because of the following well recognized properties: (1) film-forming ability,(2) excellent adhesion, (3) non-toxicity (4) good biocompatibility,(5) cross linking capability and (6) as interesting matrix for biomaterial immobilization. As mentioned above, the combination of chitosan with nanomaterials such as gold nanoparticles and carbon nanomaterials produces a suitable microenvironment for immobilizing biomolecules and for enhancing the sensitivity of the resulted sensor. Moreover, polypyrrole (PPy) was used in synthesizing polymer/CNTs composites because of its stability and high electrical conductivity

Under the optimum conditions, concentrations of E. coli from $3 \times 10^{1}$ to $3 \times 10^{7}$ $\mathrm{CFU} / \mathrm{mL}^{-1}$ were detected with a detection limit of $30 \mathrm{CFU} \mathrm{mL} \mathrm{m}^{-1}$ in PBS buffer. Good results in terms of specificity and stability were also achieved.

On the other hand, it should be mentioned that evaluating the sensor analytical parameters on real samples would have been very helpful.

A rapid, label-free aptasensor based on a hybrid nanomaterial using the actuation of chitosan $(\mathrm{CH})$ nanobrushes on graphene/nanoplatinum electrodes was developed to detect Listeria monocytogenes cells through a combination of electrostatic interactions and receptor-cell binding [81], as illustrated in Figure 6. 


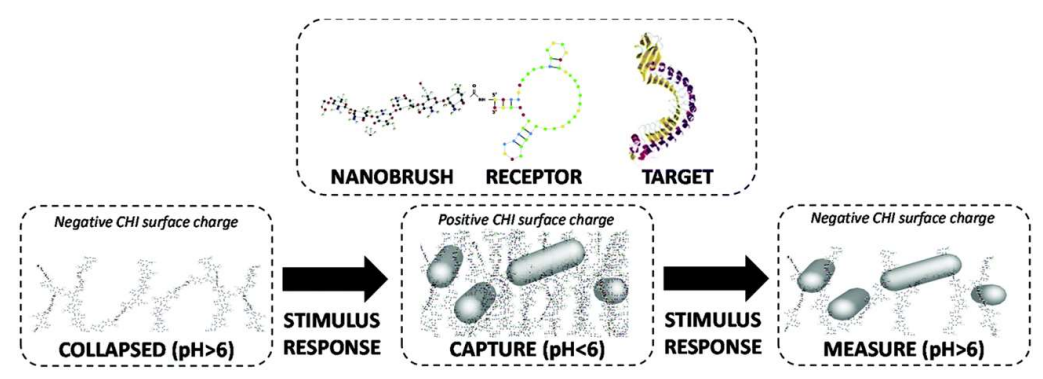

Figure 6. Nanobrush sensing strategy for selective bacteria capture. Top: Stimulus-responsive chitosan $(\mathrm{CHI})$ nanobrushes are decorated with receptors that bind a cell surface target. Bottom: Nanobrush is actuated from collapsed to extended states based on $\mathrm{pH}$ changes. The nanobrush is first extended $(\mathrm{pH}<6)$, facilitating cell capture due to a combination of electrostatic interactions and receptor-target binding, and then measurement (sensing) is conducted in the collapsed nanobrush state $(\mathrm{pH}>6)$. Reprinted with permission from [81]. Copyright 2018 Royal Society of Chemistry (RSC).

Just a brief explanation about the new biomimetic material including $\mathrm{CH}$ nanobrushes decorated with various receptors, used for capturing the bacteria cells in food samples.

The bio-inspired soft material and sensing strategy mimic natural symbiotic systems, where low levels of bacteria are selectively captured from complex matrices. To engineer this biomimetic system, reduced graphene oxide/nanoplatinum (rGO-nPt) electrodes were developed, and their electrochemical behaviour in the presence and absence of chitosan nanobrushes were characterized during actuation ( $\mathrm{pH}$-stimulated osmotic swelling). The reduced graphene oxide-nanoplatinum (rGO-nPt) electrode layer consisted of $118 \mathrm{~nm} \mathrm{nPt}$ fractal nodes on larger microstructures covering the rGO surface.

When $\mathrm{CH}$ was electrodeposited on the rGO-nPt surface, nanobrush structures with an average diameter of $126 \mathrm{~nm}$ were formed.

To characterize the electrostatic interactions during nanobrush actuation, CV curves were analysed for different redox probes at various $\mathrm{pH}$, including a negatively charged probe, a neutral probe, and a positively charged probe.

In addition, the electrochemical behaviour of the nanobrush was investigated when receptors (antibodies or DNA aptamers) are immobilized and conjugated onto the surface.

$\mathrm{CHI}$ nanobrushes were preferred to other materials because of their low cost and biocompatibility.

Finally, various techniques to determine the most efficient capture strategy based on nanobrush actuation were analysed, and then the biosensor was applied in food product commodities analysis.

Maximum cell capture was obtained when aptamers conjugated to the nanobrush bind cells in the extended conformation $($ at $\mathrm{pH}<6$ ), followed by impedance measurement in the collapsed nanobrush conformation (at $\mathrm{pH}>6$ ). The aptamer-nanobrush hybrid material was more efficient than the antibody-nanobrush material, probably due to the relatively high adsorption capacity for aptamers. The analytical characterization of the aptasensor for selectively detecting L. monocytogenes evidenced a rapid test (17 $\mathrm{min})$, a linear concentrations range from 9 to $10^{7} \mathrm{CFU} \mathrm{mL}$, with a limit of detection of $3.0 \mathrm{CFU} \mathrm{mL} \mathrm{mL}^{-1}$ in buffer with no pre-concentration, and in the presence of other bacteria such as Listeria innocua and Staphylococcus aureus. It was applied to detect L. monocytogenes in vegetal broth, but the calibration curves were non-linear, with a saturation effect probably due to non-specific binding. This non-specific binding was expected, since a vegetable broth can contain different components and ingredients, as aqueous extracts from cooked carrot/onion/celery, tomato paste, yeast extract, onion powder, potato flour, etc., thus underlying 
the importance of calibrating pathogen sensors in media specific to the application of interest.

As last and more recent example, we would like to introduce an electrochemical immunosensor [82] for the determination of Lactobacillus brevis. Lactobacillus brevis is the most common bacteria that causes beer spoilage.

The electrochemical sensor is Horseradish peroxidase labelled sandwich immunosensor, based on a nanocomposite including gold nanoparticles, chitosan, and an ionic liquid (1-Butyl-3-methylimidazolium hexafluorophosphate, IL)

In this case, gold nanoparticles (AuNPs) were firstly electrodeposited on a glassy carbon electrode for improving the conductivity and specific surface area. Ionic liquid was used for boosting the immobilization performance of the immunosensor.

Unlike the electrochemical sensor, mentioned in the subsection 4.2 [70], chitosan is not used to control the synthesis of anisotropic nanoparticles, but it has been used for further enhancing the stability of antibody because of the binding and blanketing effects [83]. After optimization, a linear concentration range was observed from $10^{4} \mathrm{CFU} / \mathrm{mL}$ to

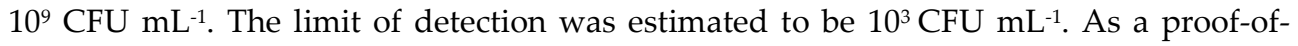
concept, the proposed immunosensor was successfully applied to spiked beer samples, obtaining good results in terms of relative standard deviation (RSD\%).

\subsection{Toxins}

Toxins are present in a natural environment. They are produced by microbes and algae. Toxins contamination is unpredictable and unavoidable. In fact, it can take place during the food production chain, including processing, transport, and storage, so causing severe economic losses and public health problems. Based on the survey from the World Health Organization (WHO), humans are exposed to toxins through the ingestion of contaminated foods, causing severe poisoning [84, 85].

Herein, we would like to show examples of electrochemical biosensors for toxins detection, employing chitosan, summarized in table 4.

Table 4. Recent examples of electrochemical chitosan-based sensors for toxins detection.

\begin{tabular}{|c|c|c|c|c|c|c|}
\hline Electrode & Sensor Format & $\begin{array}{c}\text { Electro- } \\
\text { chemical } \\
\text { Technique }\end{array}$ & Analyte/Sample & L.R. & LOD & References \\
\hline GCE & $\begin{array}{l}\text { Electrochemical immunosensor based } \\
\text { on single-walled carbon nano- } \\
\text { tubes/chitosan (SWCNTs/CHI) nano- } \\
\text { composite }\end{array}$ & SWV & $\begin{array}{c}\text { AFB1/corn } \\
\text { powder }\end{array}$ & $\begin{array}{l}0.01-100 \\
n g \mathrm{~mL}^{-1}\end{array}$ & $3.5 \mathrm{pg} \mathrm{mL}^{-1}$ & [86] \\
\hline GCE & $\begin{array}{l}\text { Label-free impedimetric aptasensor } \\
\text { based on chitosan/dipeptide nano- } \\
\text { fibrous hydrogel and immobilized } \\
\text { DNA probes with OTA aptamer }\end{array}$ & EIS & OTA/white wine & $\begin{array}{l}0.1-100 \\
\mathrm{ng} \mathrm{mL}^{-1}\end{array}$ & $0.03 \mathrm{ng} \mathrm{mL}^{-1}$ & [89] \\
\hline
\end{tabular}

Abbreviations: AFB1: aflatoxin B 1; CHI: chitosan; EIS: electrochemical impedance spectroscopy; GCE: glassy carbon electrode; OTA: ochratoxin; SWCNTs: single walled carbon nanotubes; SWV: square wave voltammetry.

As first example, we present a sensitive electrochemical immunosensor for aflatoxin B1 (AFB1) detection based on single-walled carbon nanotubes/chitosan nanocomposite (SWCNTs/CHI) [86].

Aflatoxins are detected in corn, peanuts, cottonseeds, nuts, almonds, figs, pistachios, spices, milk, and cheese and in various other food and beverages; they are stable at high temperatures. Consequently, they may resist the cooking processes [87]. Four types of aflatoxins were identified: AFB1, AFB2, AFG1, AFG2, plus two additional metabolites: AFM1 and AFM2, being AFB1 classified as the most abundant and toxic. 
Among these, AFB1 is highly toxic, carcinogenic, mutagenic, genotoxic, and immunosuppressive, it is classified as a group 1 carcinogen by International Agency for Research on Cancer (IARC), and a dose of more than $20 \mathrm{mg} / \mathrm{kg}$ bw (bw body weight) per day was associated with acute aflatoxicosis in adults [88].

SWCNTs exhibit considerable specific superficial area, so increasing the immobilizing enzymes loading, amplifying the electroactive area, improving electrical conductivity, and the (bio)sensors performance. On the other hand, with the strong attractive interaction among the nanotubes, SWCNTs cannot be spread in aqueous solution without an appropriate dispersing agent. To overcome this problem, chitosan, was therein adopted. When combined with SWCNTs, chitosan could enhance the dispersive property of SWCNTs.

The proposed immunosensor was based on an indirect competitive binding to a fixed amount of anti-AFB1 between free AFB1 and AFB1-bovine serum albumin, immobilized on covalently nanotubes/chitosan layer casted on a glassy carbon electrode[86]. Then, the anti-mouse immunoglobulin G secondary antibody labeled with alkaline phosphatase was bound to the electrode surface through reaction with primary antibody. Finally, alkaline phosphatase catalyzed the hydrolysis of the substrate $\alpha$-naphthyl phosphate, generating an electrochemical signal. A scheme of the strategy for AFB1 sensing using GCE modified with a single-walled carbon nanotubes/chitosan film is illustrated in Figure 7.

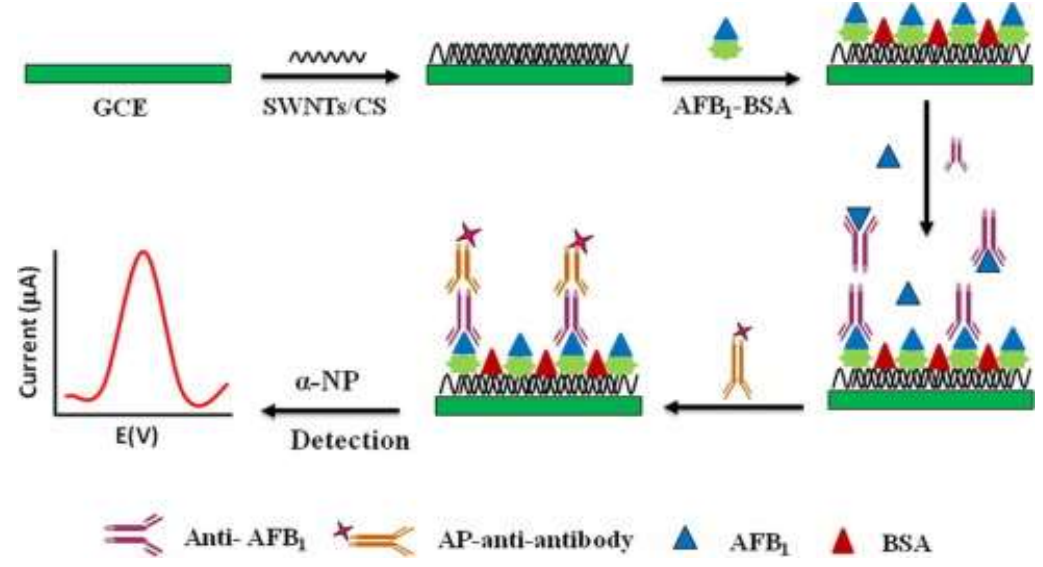

Figure 7. Scheme of the strategy for AFB1 sensing using GCE modified with a singlewalled carbon nanotubes/chitosan film. Reprinted with permission from [86]. Copyright 2016 Elsevier.

Under optimized conditions, a linear concentrations range from 0.01 to $100 \mathrm{ng} \mathrm{mL}^{-1}$ was found, with a detection limit of $3.5 \mathrm{pg} \mathrm{mL}^{-1}$. Moreover, the immunosensor was successfully applied to assay AFB1 in corn powder, and good correlation with the results obtained from high performance liquid chromatography has been evidenced.

Finally, we propose a novel label-free impedimetric electrochemical sensor consisting of chitosan/dipeptide nanofibrous hydrogel and immobilized DNA probes with OTA aptamer for the detection of ochratoxin A (OTA) [89].

OTA belongs to the ochratoxins family. The ochratoxins are secondary metabolites secreted by fungi species (e.g., Aspergillus and Penicillium) during their growth. They are present in different crops and beverages, including coffee, wine, grape juice, and dried fruits [90]. Among them, ochratoxin A (OTA) has been classified as a possible carcinogen by the International Agency for Research on Cancer (IARC) due to its severe toxicity [88], and the EFSA Panel on Contaminants in the Food Chain stated a tolerable daily intake (TDI) for OTA of $0.4 \mathrm{mg} / \mathrm{kg}$ bw [91]. In addition, OTA is chemically stable, so that it is metabolized very slowly with a half-life of more than 30 days in the body. 
Coming back to the impedimetric sensor, the thin film of chitosan/dipeptide nanofibrous hydrogel was used as sensing interface and carrier for hybridization chain reaction (HCR) of OTA aptamer and DNA2 strand to form DNA concatemer.

A concatemer is a long continuous DNA molecule containing multiple copies of the same DNA sequence linked in series.

The (tert-Butoxycarbonyl)(Boc)-phenylalanine-tryptophan-OH dipeptide hydrogel has been used as dipeptide nanofibrous hydrogel and acts as supporting material for its properties of biocompatibility and biodegradation.

Considering the chitosan role in the bionanocomposite, chitosan was introduced to enhance the immobilization stability of dipeptide hydrogel sensing film and provide a biointerface with a large number of $-\mathrm{NH}_{2}$ groups for the immobilization of carboxylmodified DNA1. As a result, the working electrode was a GCE modified with the chitosan/dipeptide nanofibrous hydrogel adherent film.

During the modification of the working electrode, a layer-by-layer thin film as a three dimensional network of dipeptide nanofibrous hydrogel and chitosan was deposited, providing amino groups easily interacting with carboxyl-DNA1.

The concatemer was dissociated to single-stranded DNA (ssDNA) in the presence of target OTA, and the signal amplification was further implemented by introducing RecJf exonuclease, which could digest the single-stranded DNA resulting in OTA recycle. A scheme of the impedimetric electrochemical sensor for OTA detection based on the chitosan/dipeptide nanofibrous hydrogels is summarized in Figure 8.

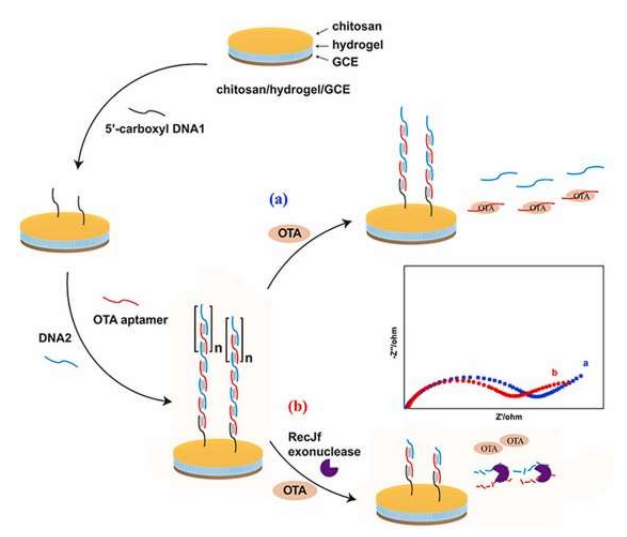

Figure 8. OTA analysis steps of the impedimetric electrochemical sensor. Reprinted with permission from [89]. Copyrigt 2021 Elsevier.

Electrochemical impedance spectroscopy (EIS) has been employed as electrochemical techinique to determine OTA. A linear detection range of $0.1-100 \mathrm{ng} \mathrm{mL}^{-1}$ was obtained for OTA, with a low detection limit of $0.03 \mathrm{ng} \mathrm{mL}^{-1}$. The sensor was applied to spiked real samples of white wine, obtaining recoveries ranging from 96 to $102.58 \%$ with the RSD values in the range of $4.58-7.8 \%$. These results indicated that the proposed sensor could effectively recognize the target molecule in a complex matrix.

\subsection{Pesticides}

Pesticides are among the most used products in the agri-food industry for the control, prevention, and elimination of pests. According to the target pest, they can be classified as insecticides, fungicides, herbicides, etc. The main classes of pesticides are carbamates, organophosphates, pyrethroids, or triazines, among others [92, 93], and all these compounds resulted highly toxic. According to the World Health Organization (WHO), they can be classified as carcinogenic, neurotoxic, or teratogenic [92]. 
The maximum residual limits (MRLs) legally permitted in the European Union are $0.1 \mu \mathrm{g} / \mathrm{L}$ for a single pesticide and $0.5 \mu \mathrm{g} / \mathrm{L}$ for total pesticides [94].

Herein, some recent examples of application of chitosan in (bio)sensors for pesticides detection are reported and summarized in table 5.

Table 5. Recent examples of electrochemical chitosan-based (bio)sensors for pesticides detection.

\begin{tabular}{|c|c|c|c|c|c|c|}
\hline Electrode & (Bio)Sensor Format & $\begin{array}{l}\text { Electrochem- } \\
\text { ical Tech- } \\
\text { nique } \\
\end{array}$ & Analyte/Sample & L.R. & LOD & References \\
\hline GCE & $\begin{array}{l}\text { Electrochemical biosensor based on } \\
\text { chitosan }(\mathrm{CHI}) \text {, TiO2 sol-gel, and re- } \\
\text { duced graphene oxide (rGO) multi- } \\
\text { layered immobilization matrix } \\
\left(\mathrm{CHI} @ \mathrm{TiO}_{2}-\mathrm{CHI} / \mathrm{rGO}\right) \text { for AChE }\end{array}$ & DPV & $\begin{array}{l}\text { Dichlorvos/cabbage } \\
\text { juice }\end{array}$ & $0.036-22.6 \mu \mathrm{M}$ & $29 \mathrm{nM}$ & [95] \\
\hline ITO & $\begin{array}{l}\text { Electrochemical sensor using ITO } \\
\text { electrode modified with poly-3,4-eth- } \\
\text { ylenedioxythiophene (PEDOT) mem- } \\
\text { brane and zirconia nanoparticles } \\
\left(\mathrm{ZrO}_{2} \mathrm{NPs}\right)\end{array}$ & 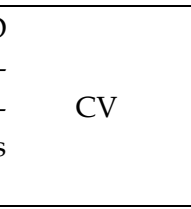 & Parathion/water & $\begin{array}{l}5-2000 \\
\mathrm{ng} \cdot \mathrm{mL}^{-1}\end{array}$ & $2.8 \mathrm{ng} \mathrm{mL}^{-1}$ & [96] \\
\hline $\begin{array}{l}\text { Fluorine-tin- } \\
\text { oxide glass } \\
\text { electrode (FTO) }\end{array}$ & $\begin{array}{l}\text { Electrochemical sensor developed by } \\
\text { immobilizing haemoglobin }(\mathrm{Hb}) \text {, on } \\
\text { electrochemically reduced graphene- } \\
\text { ) oxide-chitosan (ERGO-CHI/Hb/FTO) } \\
\text { nanocomposite }\end{array}$ & SWV & $\begin{array}{c}\text { Parathion/onion, let- } \\
\text { tuce }\end{array}$ & $\begin{array}{c}0.076-0.988 \\
\mu \mathrm{M}\end{array}$ & $79.77 \mathrm{nM}$ & [97] \\
\hline GCE & $\begin{array}{l}\text { Electrochemical sensor based on plat- } \\
\text { inum nanoparticles and chitosan } \\
\text { nanocomposite (PtNPs/CHI) }\end{array}$ & DPAdSV & Diuron/river water & - & $20 \mu \mathrm{g} \mathrm{L}^{-1}$ & [98] \\
\hline GCE & $\begin{array}{l}\text { Electrochemical sensor based on plat- } \\
\text { inum nanoparticles and chitosan } \\
\text { nanocomposite (PtNPs/CHI) }\end{array}$ & DPAdSV & $\begin{array}{l}\text { Isoproturon/river } \\
\text { water }\end{array}$ & - & $7 \mu \mathrm{g} \mathrm{L}^{-1}$ & [98] \\
\hline $\begin{array}{c}\text { Ag-cit- } \\
\text { rate/GQDs } \\
\text { nano-ink/leaf } \\
\text { or skin } \\
\end{array}$ & $\begin{array}{l}\text { Electrochemical sensor prepared by } \\
\text { direct writing on the surface of the } \\
\text { samples, using Ag-citrate/graphene } \\
\text { quantum dots (GQDs) nano-ink }\end{array}$ & $\mathrm{DPV}, \mathrm{SWV}$ & $\begin{array}{c}\text { Trifluralin/apple } \\
\text { skin }\end{array}$ & $\begin{array}{l}0.005-0.04 \\
\mathrm{mM}\end{array}$ & $0.005 \mathrm{mM}$ & [99] \\
\hline GCE & $\begin{array}{l}\text { Electrochemical sensor based on } \\
\text { quantum dots, chitosan, and nickel } \\
\text { molybdate nanocomposites } \\
\text { (GQDs/CHI/ } \mathrm{NiMoO}_{4}\end{array}$ & DPV & $\begin{array}{l}\text { Diazinon/tomato } \\
\text { and cocumber }\end{array}$ & $0.1-330 \mu \mathrm{M}$ & $30 \mathrm{nM}$ & [102] \\
\hline
\end{tabular}

Abbreviations: AChE: acetylcholinesterase; CHI: chitosan; CV: cyclic voltammetry; DPAdSV: differential pulse adsorptive stripping voltammetry; DPV: differential pulse voltammetry; ERGO: electrochemical reduced graphene oxide; FTO: Fluorine-tin-oxide; GCE: glassy carbon electrode; GQDs: graphene quantum dots; ITO: indium tin oxide; Hb: haemoglobin; MWCNTs: multi-walled carbon nanotubes; rGO: reduced graphene oxide; SWV: square wave voltammetry.

A stable electrochemical acetylcholinesterase (AChE) biosensor [95] for detection of organophosphorus pesticides (OPs) was developed by adsorbing AChE on chitosan $(\mathrm{CH})$, $\mathrm{TiO} 2$ sol-gel, and reduced graphene oxide (rGO) based multi-layered immobilization matrix $\left(\mathrm{CH} @ \mathrm{TiO}_{2}-\mathrm{CHI} / \mathrm{rGO}\right)$. The matrix has a mesoporous nanostructure. In fact, the rGO nanosheets have a graphene typical wrinkle surface morphology. The $\mathrm{TiO}_{2}$ sol-gel film 
shows a homogeneous mesoporous morphology. With the incorporation of $\mathrm{CH}$, the surface become rougher, and the nanoparticles get bigger. The content of $\mathrm{TiO}_{2}$ has no particular effect on the surface morphology. The electrodeposited CHI layer induces the formation of nanoparticle aggregates, but the surface is still rough and porous. At the end, incorporation of $\mathrm{CH}$ and electrodeposition a $\mathrm{CH}$ layer into/on the $\mathrm{TiO}_{2}$ sol-gel improve the gel mechanical properties.

AChE loading fills the pores, and the resulting surface is more regular. The rough and porous surface morphology would facilitate a stable AChE immobilization.

The linear concentrations range for the detection of dichlorvos, as model OP compound, was from $0.036 \mu \mathrm{M}(7.9 \mathrm{ppb})$ to $22.6 \mu \mathrm{M}$, with a limit of detection of $29 \mathrm{nM}(6.4$ $\mathrm{ppb})$. Finally, the biosensor was applied to the detection of dichlorvos in spiked cabbage juice samples. The recovery ratios were all within the range of $100 \pm 3 \%$, the RSDs were less than $10.0 \%$, indicating a possible accurate OPs detection with the biosensor.

Liu and co-workers developed an electrochemical sensor [96] for detection of another organophosphorus pesticide, such as methyl parathion, based on an indium tin oxide (ITO) electrode modified with a nanocomposite including zirconia oxide nanoparticles ( $\left.\mathrm{ZrO}_{2} \mathrm{NPs}\right)$, poly 3,4-ethylenedioxythiophene (PEDOT), and chitosan (CHI).

Firstly, PEDOT was electrodeposited onto the electrode surface and then a colloid containing $\mathrm{ZrO}_{2} \mathrm{NPs}$ and $\mathrm{CHI}$ was dropped on it.

Chitosan improves the stability of zirconia nanoparticles and, as can be seen from the morphology of $\mathrm{ZrO}_{2} \mathrm{NPs}-\mathrm{CHI} /$ PEDOT/ITO electrode surface, it induces an aggregation of the zirconia nanoparticles. Moreover, the chitosan membrane is flat, but it has some cracks, which produce channels between solution and PEDOT/ITO. The aggregation of zirconia nanoparticles on PEDOT supports the adsorption of MP, and the cracks of chitosan membrane allow to access the polymer.

Even if the chitosan decreases the background current, the accumulative effect of $\mathrm{ZrO}_{2}$ and the conductivity and electrocatalytic activity of PEDOT improve the total redox process. Under optimized conditions, a limit of detection of $2.8 \mathrm{ng} \mathrm{mL}^{-1}$ and a linear range of 5-2000 ng mL-1 were obtained. Furthermore, the sensor was applied to spiked tap water real samples, with interesting results in terms of recovery, ranging from $93.5 \%$ to $104.7 \%$.

Another electrochemical sensing tool using a bioelectrode based on redox active protein haemoglobin $(\mathrm{Hb})$ is offered here for the determination of methyl parathion [97]. A scheme of the methyl parathion electrochemical sensor assembling is illustrated in Figure 9.

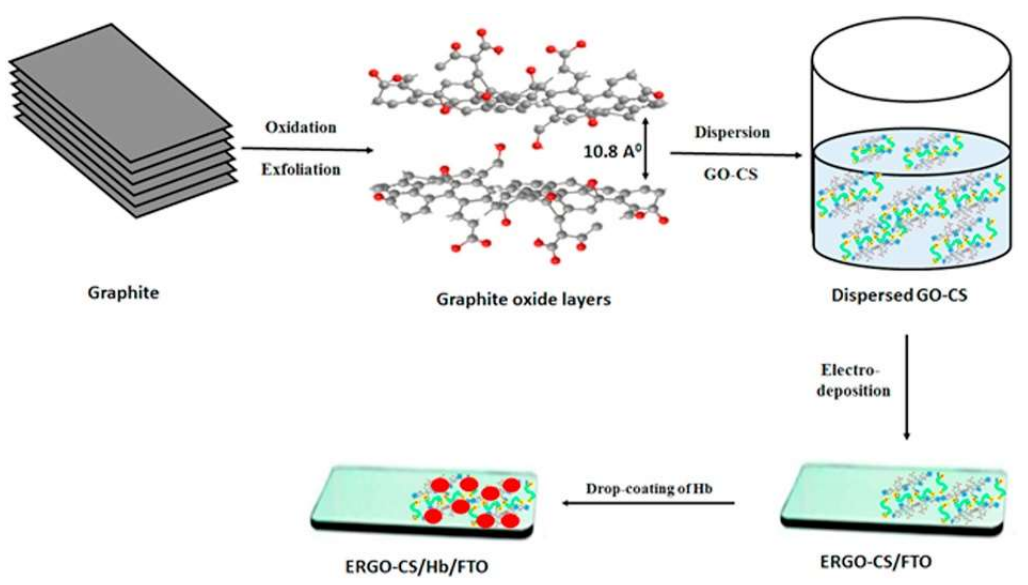

Figure 9. Scheme of the methyl parathion sensor assembling steps. Reprinted with permission from [97]. Copyright 2020 Elsevier. 
The bioelectrode was assembled immobilizing $\mathrm{Hb}$ on a fluorine doped tin oxide (FTO) electrode modified with electrochemically reduced graphene oxide-chitosan $($ ERGO-CHI/Hb) based biocompatible layers. Chitosan was mixed with reduced graphene oxide, as previously mentioned in the subsection 4.3 for a Salmonella aptasensor [77], to increase its conductivity. Also in this case, the chitosan properties, such as biological renewability, hydrophilicity, biodegradability, with good film forming ability and large mechanical strength, were integrated by those of graphene oxide, such as high surface area, high electron transfer rate together with lower background currents, and wide potential window. Finally, the electrochemically reduced graphene oxide-chitosan layers (ERGO$\mathrm{CHI}$ ) was used as immobilizing platform of $\mathrm{Hb}$. The biocompatible ERGO-CHI matrix promotes the direct electron transfer from protein to the electrode surface without the breakdown of native protein structure.

The sensor showed a low limit of detection of $79.77 \mathrm{nM}$, with a good reproducibility. The modified biosensor was applied to detect MP in spiked vegetable samples, with good results in terms of recovery ranging from $94 \%$ to $101 \%$.

A simple method for the simultaneous electrochemical determination of two phenylurea herbicides (diuron and isoproturon) by differential pulse adsorptive stripping voltammetry (DPAdSV) using a modified platinum/chitosan electrode [98] has been reported. Chitosan (CHI) can be a good choice to stabilize metallic nanoparticle by stereoelectronic effects providing nanocomposites with high functionality. This can occur because $\mathrm{CHI}$ has a great affinity for transition metals and good-film form properties. The amino groups of the resultant nanocomposite improve the capability of the modified electrode to bind in other polymers and inorganic materials, producing films with good adhesion on the negatively charged and porous surfaces. Also, high permeability enables the diffusion process of the analyte on the modified electrode surface. The combined properties of these bio-based materials can be a key point in the development of high-performance sensors.

PtNPs were synthesized by a one-step reaction using $\mathrm{CH}$ as a stabilizer agent. The resulting bionanocomposite was applied in the assembling of a modified glassy carbon electrode (PtNPs/CH/GCE) for the rapid, selective, and low-cost simultaneous analysis of diuron and isoproturon in river water samples.

Under the optimized conditions, the limit of detection was $7 \mu \mathrm{g} \mathrm{\textrm {L } ^ { - 1 }}$ for isoproturon and $20 \mu \mathrm{g} \mathrm{L}^{-1}$ for diuron. The proposed method was successfully applied to the determination of both analytes in spiked river water samples, with a recovery range of $90-110 \%$

A very particular and ecofriendly method [99] was developed to determine trifluralin. Trifluralin is an herbicide affecting endocrine function, and so it is listed as an endocrine disruptor in the European Union list [100].

The trifluralin sensor is based on its electrochemical oxidation on a three-electrode system designed directly on the surface of an agricultural product, using Ag-citrate/GQDs (graphene quantum dots) nano-ink. The sensor was prepared by writing directly on the surface of the samples, obtaining, for example, Ag-citrate/GQDs nano-ink/leaf electrode if testing trifluralin in an apple. Chitosan is present in the nano-ink with the role of dispersing and supporting matrix of GQDs and Ag nanoparticles, as usual. It has to be pointed out that the interaction mechanism of trifluralin on the prepared Ag-citrate/GQDs nano-ink/leaf electrode is based on electrostatic interactions, probably, between the dipole nitro group of trifluralin with negative charge and protonated amine group of chitosan previously diluted in acetic acid, involving $\mathrm{Ag}^{+}$group of Ag-citrate present in the conductive nano-ink [101].

Under the optimized experimental conditions, this sensor exhibited good sensitivity and specificity for trifluralin detection. The obtained linear range was between 0.008 to 1 $\mathrm{mM}$, and the limit of quantification was $0.008 \mathrm{mM}$, using cyclic voltammetry. In addition, the obtained linear range using differential pulse voltammetry (DPV) and square wave 
voltammetry (SWV) was $0.005-0.04 \mathrm{mM}$ with the limit of quantification of $0.005 \mathrm{mM}$. For further validation of the applicability of the proposed method, it was also used to detect trifluralin on the surface of apple skin.

A sensitive and selective electrochemical sensor was reported based on the modification of activated glassy carbon electrode (GCEox) with graphene quantum dots (GQDs), chitosan, and nickel molybdate $\left(\mathrm{NiMoO}_{4}\right)$ nanocomposites for diazinon determination. The sensor assembling strategy was based on covalent immobilization of polymer and nanoparticle on the GCEox surface [102].

Diazinon is classified as an organophosphorus pesticides and acts as inhibitor of cholinesterase (ChE) function. As already mentioned, and discussed, chitosan is selected as supporting matrix for its film forming capability, its water permeability, fast ion exchange property, adhesion to hydrophilic surfaces, easy chemical modifications, and presence of suitable functional groups. $\mathrm{NiMoO}_{4}$ was selected because of its interesting properties for application to an electrochemical sensor design such as high electrical conductivity, chemical stability, low-cost, enhanced electrochemical performance, among others.

The GCE was activated by means of cyclic voltammetry oxidative scans in acidic medium: functional groups such as hydroxyl oxygen $\left(\mathrm{O}^{-}\right)$and carbonyl oxygen $\left(\mathrm{COO}^{-}\right)$ groups were inserted onto the GCE surface, so introducing negative charges on the electrode surface [103]. Chitosan was immobilized on the surface of GCEox, through the electrostatic attraction between ammonium groups of $\mathrm{CHI}$ and functional groups of the electrode surface (carboxyl and hydroxyl groups) to prepare CHI/GCEox. Next, CHI/GCEox was immersed in the GQDs solution to form GQDs/CHI/GCEox. The plentiful presence of functional groups, especially carboxyl groups in the GQDs, provided strong covalence bonding between GQDs with amino groups of $\mathrm{CHI}$ and created functional groups on the activated electrode surface. Finally, $\mathrm{NiMoO}_{4}$ nanoparticles suspension was casted on the modified electrode surface. Under the optimized conditions, a linear concentrations range from 0.1 to $330 \mu \mathrm{M}$ and a limit of detection of $30 \mathrm{nM}$ using DPV were obtained. The sensor was applied to the determination of diazinon in spiked real samples of tomato and cucumber, obtaining acceptable results in terms of recovery ranging from 106 to $101 \%$.

\subsection{Contaminants and additives}

Endocrine-disrupting chemicals (EDCs) are environmental contaminants/pollutants and are also known as hormone-disrupting compounds [104].

The WHO is particularly sensitive to the problem of the presence and determination of endocrine disrupters [105].

Furthermore, EDCs represent a broad class of molecules, such as pesticides (see, for example, trifluralin [100]) and industrial chemicals, plastics and plasticizers, fuels, and many other chemicals present in the environment.

Herein, we focused our attention on bisphenol A (BPA), one of the most important endocrine disruptor.

Bisphenol A (BPA) is a synthetic chemical, classified as a non-biodegradable compound with high chemical resistance and widely used as a monomer in the synthesis of epoxy resins and polycarbonate. BPA has a similar structure to that of estradiol and diethylstilbestrol and thus can stimulate a cellular response, binding with the estrogen receptors. For this reason, is classified as endocrine disrupting chemical.

Polycarbonates have different applications, particularly in the fabrication of water bottles, infant feeding bottles, and it can be usually transferred into drinks and food from plastic products. On the other hand, epoxy resins are widely used as protective coatings for food and beverage containers, so BPA can produce contamination of food commodities and water.

A multi-walled carbon nanotube (MWCNT) based molecularly imprinted polymer (MIP) was successfully developed and used for modifying glassy carbon electrode (GCE) for the electrochemical detection of BPA [106]. The MIP was synthesized on the surface of 
silica coated CNTs. Glycidoxy propyl trimethoxy silane (GLYMO), with organic epoxide and hydrolysable methoxysilyl groups, was used as bifunctional silylating agent because of its mechanical and adhesion properties [107]. MIP was prepared in an easy and conventional way by co-polymerization of functional monomers vinylpyridine (4-VPy) and methacrylic acid (MAA) with the cross-linker ethylene glycol dimethylacrylate (EDGMA). In addition to the $\mathrm{H}$-bonding interaction evidenced by both the monomers, the $\pi-\pi$ stacking interaction between pyridinyl and phenyl ring contribute to better selectivity and sensitivity of the prepared MIP. Chitosan acted as supporting matrix for the MIP also integrating its mechanical and tensile properties, producing also a strengthened matrix for electrode coating. A well defined electrochemical response was obtained for BPA by cyclic voltammetry and differential pulse voltammetry. Under the electrochemical optimized conditions, a linear concentrations range from $400.00 \mathrm{mM}$ to $0.10 \mathrm{nM}$ with detection limit of $0.02 \mathrm{nM}$ was obtained. The MIP/GCE sensor was evaluated towards the determination of BPA in commercially available baby feeding bottle samples. BPA was extracted in ethanol at $55^{\circ} \mathrm{C}$ for $24 \mathrm{~h}$ and then the exctracts have been concentrated and analysed. The results were in good agreement with those obtained by HPLC.

Graphene nanoplatelets (GNPs), multiwalled carbon nanotube (MWCNTs) and chitosan $(\mathrm{CHI})$ were self-assembled by means of one-step hydrothermal reaction to obtain a nanocomposite (GNPs-MWCNTs-CHI) [108]. Chitosan acted as a supporting and dispersing matrix for GNPs and MWCNTs, and the nanocomposite stability was improved by the electrostatics interactions among CHI, GNPs and MWCNTs. In addition, GNPsMWCNTs also showed better stability than GNPs or MWCNTs due to the $\pi-\pi$ stacking interactions between GNPs and MWCNTs. GNPs-MWCNTs/CHI/GCE) were investigated using cyclic voltammetry (CV) and electrochemical impedance spectroscopy (EIS). The GNPs-MWCNTs-CHI/GCE was used for the determination of bisphenol A (BPA) by differential pulse voltammetry (DPV). Under the optimum conditions, the linear BPA concentration range was $0.1-100 \mu \mathrm{M}$, with a detection limit of $0.05 \mathrm{nM}$.

The proposed GNPs-MWCNTs-CHI/GCE based sensor showed good selectivity, repeatability, and reproducibility. The sensor was applied to determine BPA in milk real samples including liquid milk samples and milk powders. The results were promising and acceptable in terms of recoveries ranging from $85.0-113.8 \%$.

A three-dimensional hierarchical nickel nanoparticles/nitrogen-doped carbon nanosheet/chitosan nanocomposite (NiNPs/NCN/CHI) was used for modifying a glassy carbon electrode (GCE) to assemble an electrochemical sensor for BPA detection [109], as shown in Figure 10.

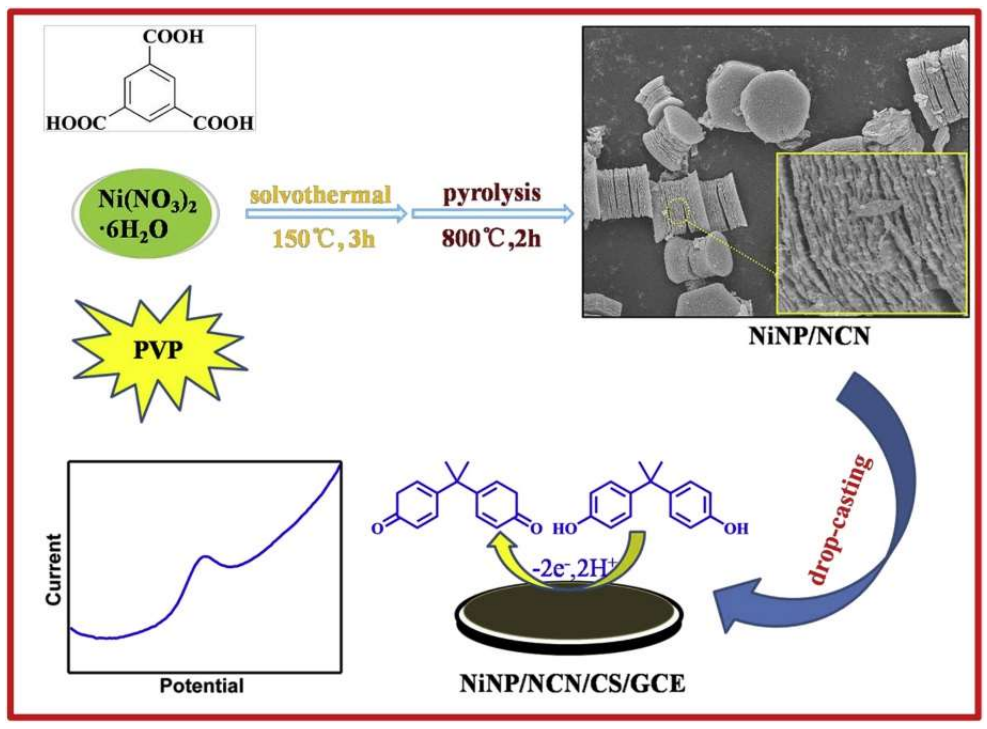


Figure 10. Synthesis of the three-dimensional hierarchical cylinder-like NiNP/NCN nanocomposite, and the assembling steps of the NiNP/NCN/CHI/GCE-based electrochemical BPA sensor. Reprinted with permission from [109]. Copyright 2020 Elsevier.

As reported in the literature [110, 111], NiNPs exhibit similar properties to noble metal nanoparticles. Hence, nickel nanoparticles can be applied as substitutes for noble metals for assembling electrochemical sensor. However, nickel nanoparticles on the electrode surface are easily oxidized, so reducing active surface area, decreasing conductivity, stability, and so on $[110,111]$. Consequently, the sensor performances such as sensitivity and reproducibility get worse. The immobilization of NiNP onto carbon supporting nanomaterials prevented the oxidation of NiNPs, and thus improved the electrochemical sensors performances [112]. In addition, chitosan (CHI) was involved in the nanocomposite formulation, because it has excellent film-forming property and good antifouling ability [113]. Therefore, the nickel nanoparticle/carbon nanocomposite together with chitosan was chosen as the chemically modified electrode material to construct an electrochemical sensor for BPA detection. For the BPA analysis, two linear concentration ranges, from 0.1 to $2.5 \mu \mathrm{M}$ and from 2.5 to $15.0 \mu \mathrm{M}$, were obtained. The detection limit for BPA was $45 \mathrm{nM}$. Additionally, the BPA sensor was selective and stable. It was applied to detect BPA in spiked milk samples, obtaining recoveries ranging from 96 to $105 \%$, and RSD values less than $5 \%$, so indicating that this proposed sensor could be applied for BPA detection in milk samples.

We now turn to some examples of chitosan-based sensors for the determination of additives. Food additives/preservatives play an essential role in the food industry, as well as the protective mechanism as a retarder of degradation and/or oxidation reactions in food products, even at low concentrations.

Sulfites are among the most used additives and preservatives for food and pharmaceutical industries, because of their anti-oxidizing and anti-septic effects against food degradation. In addition, sulfites are added to fruits and vegetables to prevent "browning" and decomposition [114]. Further, they are also employed to maintain effectiveness and stability of some drugs [115]. Despite the aforementioned utilization of sulfites, their excessive concentration in the body has a lot of negative effects such as anaphylaxis, urticaria and angioedema, and gastro-intestinal problem, among others [115]. For this reason, the US Food and Drug Administration (USFDA) advised placement of caution on any food and drugs containing $10 \mathrm{mg} / \mathrm{kg}$ sulfite respectively[116].

A non-enzymatic sensor for sulfite has been developed by Marwani [117], based on polypyrrole-chitosan biocomposite modified glassy carbon electrode.

Polypyrrole and chitosan were specifically selected because of their functionalities. For instance, polypyrrole is a conducting polymer because of delocalized $\pi$ electrons enhancing the mobility of ions, polarons, solitons and bipolarons [118]. The electrical conductivity could be further improved including dopants ( $\mathrm{p}$-doing) into the polymeric matrix [117]. Chitosan is a natural biopolymer with good biocompatibility and its amine group and hydroxyl moieties could improve hydrogen bonding to the polypyrrole backbone [117]. Further, the combination of PPY with chitosan increases its adhesion onto the electrodic surface. The synthesized PPY-CHI film was used for sulfite detection using differential pulse voltammetric, with detection limit of $0.21 \mu \mathrm{M}$ and linearity ranging from 50 to $1100 \mu \mathrm{M}$.

Real samples of malt drinks and fruit juices were used to verify the applicability of PPY-CHI/GCE for determining sulfites in beverage drinks. Promising and interesting results in terms of recoveries, ranging from 92 to $104 \%$, were obtained.

Among different food additives, we have focused our attention on butylated hydroxyanisole (BHA), a potent chemical antioxidant. It is mainly used as a phenolic 
preservative and antioxidant in commercial products, such as foods, pharmaceuticals, cosmetics, and animal feeds [118].

Generally it has been added to foods containing fat because it prevent the fat rancidification, producing unpleasant odours. BHA is known as E320 food additive. Nevertheless, BHA is irritating to the skin and eyes. It has been considered as possible carcinogenic, producing also other toxic effects, if its maximum permitted level is exceeded [119]. Indeed, the amount of BHA is limited to $100 \mu \mathrm{g} \mathrm{g}^{-1}$ when used alone and $200 \mu \mathrm{g} \mathrm{g}^{-1}$ of the total amount when used in mixture with other additives [120].

An electrochemical sensor for the analysis of BHA in foodstuffs was developed using chitosan (CHI) capped with gold nanoparticles (AuNPs) [121], as illustrated in Figure 11.

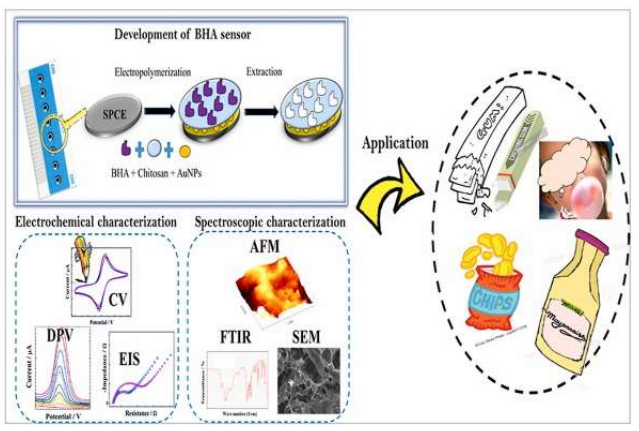

Figure 11. Schematic rapresentation of the BHA sensor assembling, characterizaion and application. Reprinted with permission from [121]. Copyright 2021 Elsevier.

The nanocomposite were self-assembled on a screen-printed carbon electrode (SPCE) and was used as molecularly imprinted polymer (MIP) employing BHA as template. An electrochemical polymerization process was chosen to design the MIP, using cyclic voltammetry as electrochemical technique, as illustrated in Figure 12.

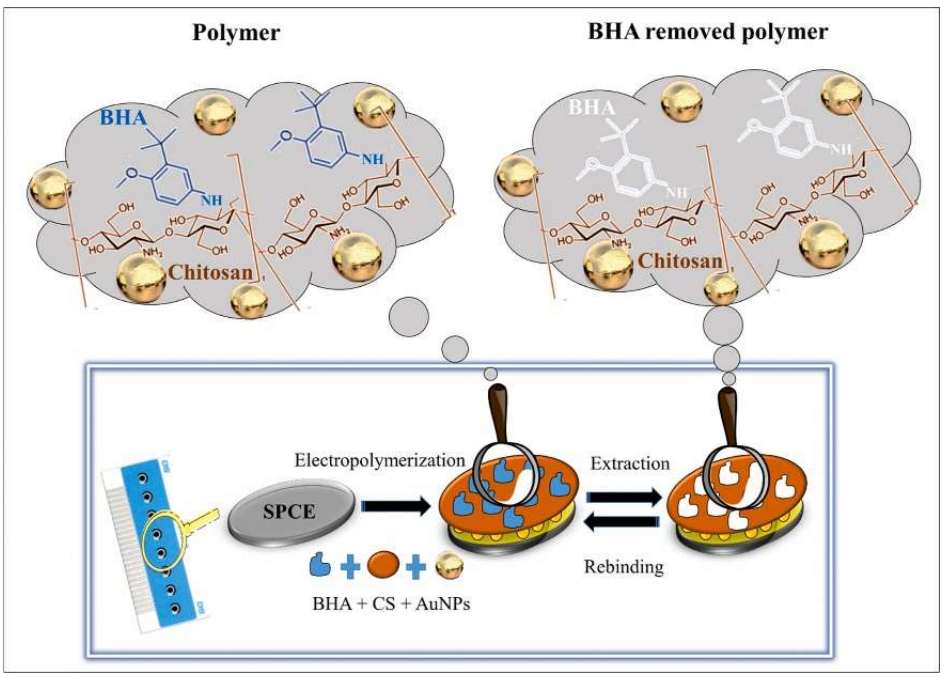

Figure 12. Scheme of the molecular architecture of the BHA-imprinted sensor. Reprinted with permission from [121]. Copyright 2021 Elsevier

As already mentioned, $\mathrm{CHI}$ presents a large number of amino $\left(-\mathrm{NH}_{2}\right)$ and hydroxyls $(-\mathrm{OH})$ groups in the polymer backbone, several reaction sites, and highly crosslinking 
degree as well as good stability. On the other hand, AuNPs nanocomposites possess large surface area and high conductivity. In this example, the appropriate choice of CHI polymer is based on its $-\mathrm{NH}_{2}$ groups, possibly interacting with the $-\mathrm{OH}$ groups of the BHA through hydrogen bond. This allows forming peculiar self-assembly network provided with several recognition sites for imprinted polymer [122].

The MIP sensor exhibited good sensitivity and selectivity vs. BHA compared to interfering species such as ascorbic acid and citric acid. Under optimal experimental conditions, it showed a linear concentrations range from 0.01 to $20 \mu \mathrm{g} \mathrm{mL}^{-1}$, with a low detection limit of $0.001 \mu \mathrm{g} \mathrm{mL}^{-1}$. Besides, reproducibility, stability, and repeatability of the MIP sensor were tested. The MIP sensor was applied for detecting BHA in real spiked food samples such as chewing-gum, mayonnaise, and potato chips, with a relative standard deviation RSD $\leq 8 \%$. Spectrophotometry was utilized as a validation method with acceptable results.

In table 6 are summarized the examples of chitosan-based sensors for determination of contaminants and additives.

Table 6. Recent examples of electrochemical chitosan-based (bio)sensors for contaminants and additives detection.

\begin{tabular}{|c|c|c|c|c|c|c|}
\hline Electrode & (Bio)Sensor Format & $\begin{array}{c}\text { Electro- } \\
\text { chemical } \\
\text { Technique }\end{array}$ & Analyte/Sample & L.R. & LOD & $\begin{array}{l}\text { Refer- } \\
\text { ences }\end{array}$ \\
\hline GCE & $\begin{array}{l}\text { Electrochemical sensor based } \\
\text { on multi-walled carbon nanotube } \\
\text { based molecularly imprinted poly- } \\
\text { mer and chitosan } \\
\text { (MWCNT/MIP/CHI) } \\
\text { nanocomposite }\end{array}$ & DPV & $\begin{array}{l}\text { BPA/ baby feeding } \\
\text { bottle }\end{array}$ & $400.00 \mu \mathrm{M}-0.10 \mathrm{nM}$ & $0.02 \mathrm{nM}$ & [106] \\
\hline GCE & $\begin{array}{l}\text { Electrochemical sensor using as } \\
\text { sensing platform multi-walled car- } \\
\text { bon nanotubes and chitosan } \\
\text { (MWCNTs-CHI) self-assembled } \\
\text { on graphene nanoplatelets GNPs } \\
\text { (GNPs-MWCNTs-CHI) }\end{array}$ & DPV & $\mathrm{BPA} / \mathrm{milk}$ & $0.1-100 \mu \mathrm{M}$ & $0.05 \mathrm{nM}$ & [108] \\
\hline GCE & $\begin{array}{l}\text { Electrochemical sensor based on } \\
\text { three-dimensional hierarchical cyl- } \\
\text { inder-like nickel nanoparticle/ni- } \\
\text { trogen-doped carbon } \\
\text { nanosheets/chitosan nanocompo- } \\
\text { site (NiNP/NCN/CHI) }\end{array}$ & DPV & BPA/milk & $\begin{array}{c}0.1-2.5 \mu \mathrm{M} \text { and } \\
2.5-15.0 \mu \mathrm{M}\end{array}$ & $45 \mathrm{nM}$ & [109] \\
\hline GCE & $\begin{array}{l}\text { Electrochemical sensor based on } \\
\text { polypyrrole /chitosan composite } \\
\text { (PPY/CHI) }\end{array}$ & DPV & $\begin{array}{l}\text { sulfite/malt drink and } \\
\text { orange juice }\end{array}$ & 50-1100 $\mu \mathrm{M}$ & $0.21 \mu \mathrm{M}$ & [117] \\
\hline GCE & $\begin{array}{l}\text { Electrochemical sensor based on } \\
\text { MIP included chitosan capped } \\
\text { with gold nanoparticles }\end{array}$ & DPV & $\begin{array}{l}\text { BHA/chewing-gum, } \\
\text { mayonnaise, potato } \\
\text { chips }\end{array}$ & $0.01-20 \mu \mathrm{g} \mathrm{mL}^{-1}$ & $0.001 \mu \mathrm{g} \mathrm{mL}^{-1}$ & [121] \\
\hline
\end{tabular}

Abbreviations: CHI: chitosan; CV: cyclic voltammetry; BHA: butylated hydroxyanisole: BPA: bisphenol A DPV: differential pulse voltammetry; GCE: glassy carbon electrode; GNPs: graphene nanoplatelets; MWCNTs: multi-walled carbon nanotubes; NCN: nitrogen doped carbon nanosheet; PPY: polypyrroe. 


\section{Conclusions}

The development of highly sensitive, reliable, robust, portable, and cost-effective sensing approaches has become fundamental to guarantee food safety, addressing the critical issue of infection/contamination of food commodities due to several causes, such as bacteria, contaminants, toxins, etc.

Considering the drawbacks of the conventional analytical approaches, such as complex analytical protocols, long duration of the analytical procedure, costly operation, and skilled personnel, it is quite clear that the biosensing approach is very attractive for many reasons: easy to handle, relatively low cost, good sensitivity, and easy miniaturization.

In this context, chitosan is considered a good ingredient for the development of electrochemical sensors and biosensors. Indeed, the combination of chitosan with nanoparticles and conductive polymers has provided a sensitive determination of the analyte, by increasing surface area and electron transfer. Also, chitosan has proven its efficiency to be employed as an immobilization platform for biomolecules using different approaches. It is to underline that developed chitosan incorporated sensors demonstrated a wide linear dynamic range and interesting results in terms of limit of detection. Hence, we conclude that all these sensors have the prospective to be applied in other fields of applications and real time investigation of target molecules, because chitosan showed high film forming capability, non-toxicity, biocompatibility, and biodegradability.

Although the majority the described sensors demonstrated a possible usefulness for food analysis area, they have been validated only in the laboratory. In fact, the number of the corresponding commercially available sensors is very limited. Precise and accurate validation studies are strongly suggested for a real employment of these electrochemical sensors for food and beverage safety testing. In addition, the impacts of environmental constraints, storage, selectivity, the matrix effects due to the complexity of food samples, and stability under real operative conditions must be verified. The validation and testing of statistically relevant numbers of samples, comparability, and inter-laboratory studies to validate the robustness of such sensing platforms are the next critical steps for the achievement of industry level acceptance and regulatory approvals. It would be highly beneficial if these sensors were to be introduced by the food industry to monitor the safety and the quality of processed food and beverages.

Moreover, studies of the toxicity and degradation of the nanomaterials are required. All these issues should be further addressed before the introduction to the sensors market.

Author Contributions: Writing-original draft preparation, A.C. ; writing-review and editing, A.C, R..P., F.S., and M.P. All authors have read and agreed to the published version of the manuscript

Funding This research received no external funding.

Acknowledgments: The authors would thank Alessandro Trani for the technical support

Conflicts of Interest: The authors declare no conflict of interest

\section{References}

1. Rodriguez, R.S.; O'Keefe, T.L.; Froehlich, C.; Lewis, R.E.; Sheldon, T.R.; Haynes, C.L. Sensing Food Contaminants: Advances in Analytical Methods and Techniques. Anal. Chem. 2021, 93, 23-40.

2. Curulli, A. Electrochemical Biosensors in Food Safety: Challenges and Perspectives. Molecules 2021, $26,2940$.

3. Caballero, B.; Trugo, L.; Finglas, P. Encyclopedia of Food Sciences and Nutrition: Volumes 1-10; Elsevier: New York, NY, USA, 2003.

4. Pividori, M.I.; Alegret, S. Electrochemical biosensors for food safety. Contrib. Sci. 2010, 6, 173-191.

5. Curulli, A. Nanomaterials in Electrochemical Sensing Area: Applications and Challenges in Food Analysis. Molecules 2020, 25, 5759. 
6. Hench, L. L., Biomaterials: a forecast for the future, Biomaterials 1998, 19, 1419-1423.

7. Peter, M. G., Applications and Environmental Aspects of Chitin and Chitosan. J. Macromol. Sci. A 1995, 32, 629640.

8. Islam S.; Shahid M.; Mohammad F.; Green Chemistry Approaches to Develop Antimicrobial Textiles Based on Sustainable Biopolymers: A Review. Ind. Eng. Chem. Res. 2013, 52, 5245-5260.

9. Zeng, J. B.; He, Y. S.; Li, S. L.; Wang, Y. Z.. Chitin whiskers: An overview. Biomacromolecules 2012, $13,1-11$.

10. Jayakumar, R.; Nwe, N.; Tokura, S.; Tamura, H.. Sulfated chitin and chitosan as novel biomaterials. Int. J. Biol. Macromol. 2007, 40, 175-181.

11. Garcia, A.; Peniche-Covas, C.; Chico, B.; Simpson, B. K.; Villalonga, R.. Ferrocene Branched Chitosan for the Construction of a Reagentless Amperometric Hydrogen Peroxide Biosensor. Macromol. Biosci. 2007, 7, 435-439.

12. Dotto, G. L.; Vieira, M. L. G.; Pinto, L. A. A.. Kinetics and Mechanism of Tartrazine Adsorption onto Chitin and Chitosan. Ind. Eng. Chem. Res. 2012, 51, 6862-6868.

13. Anslyn E.V.; Wang B.. Preface in Chemosensors Principles, Strategies, and Applications, Editors B. Wang, E. V. Anslyn, Publisher John Wiley \& Sons, Inc., Hoboken, New Jersey, 2011, p. xi.

14. Bandodkar A. J.; Wang J.. Non-invasive wearable electrochemical sensors: a review. Trends in Biotechnology 2014, 32, 363-371.

15. International Union of Pure and Applied Chemistry. Analytical Chemistry Division Commission on General Aspects of Analytical Chemistry, Chemical Sensors Definitions and Classification. PureEAppl. Chem. 1991, 63, 1247-1250.

16. Campuzano, S.; Yáñez-Sedeño, P.; Pingarrón, J.M. Electrochemical Affinity Biosensors in Food Safety. Chemosensors 2017, 5, 8 .

17. Yoo, E.-H.; Lee, S.-Y. Glucose Biosensors: An Overview of Use in Clinical Practice. Sensors 2010, 10, $4558-4576$.

18. Patris, S.; Vandeput, M.; Kauffmann, J.M. Antibodies as target for affinity biosensors. TrAC Trends Anal. Chem. 2016, 79, 239-246.

19. Bonizzoni, M.; Anslyn, E.V. Combinatorial Methods for Chemical and Biological Sensors. J. Am. Chem. Soc. 2009, 131, 14597-14598.

20. Bard, A.J.; Faulkner, L.R. Electrochemical Methods: Fundamentals and Applications, 2nd ed.; John Wiley \& Sons: New York, NY, USA, 2001.

21. Bartlett, P.N. Bioelectrochemistry 45: Fundamentals, Experimental Techniques, and Applications; John Wiley \& Sons: Hoboken, NJ, USA, 2008.

22. Bonizzoni, M.; Anslyn, E.V. Combinatorial Methods for Chemical and Biological Sensors. J. Am. Chem. Soc. 2009, 131, 14597-14598.

23. Suni, I.I. Impedance methods for electrochemical sensors using nanomaterials. TrAC Trends Anal. Chem. 2008, 27, 604-611.

24. Katz, E.;Willner, I. Probing Biomolecular Interactions at Conductive and Semiconductive Surfaces by Impedance Spectroscopy: Routes to Impedimetric Immunosensors, DNA-Sensors, and Enzyme Biosensors. Electroanalysis 2003, 15, 913-947.

25. Bockris, J.O.M.; Reddy, A.K.N.; Gamboa-Aldeco, M. Modern Electrochemistry 2A: Fundamentals of Electrodics, 2nd ed.; Kluwer Academic/Plenum Publishers: New York, NY, USA, 2000; Volume 2.

26. Manikandan, V.S.; Adhikarib, B.R.; Chen, A. Nanomaterial based electrochemical sensors for the safety and quality control of food and beverages. Analyst 2018, 143, 4537-4554.

27. Teradal, N.L.; Jelinek, R. Carbon Nanomaterials: Carbon Nanomaterials in Biological Studies and Biomedicine. Adv. Healthc. Mater. 2017 6, 1700574.

28. Pumera, M. Graphene-based nanomaterials and their electrochemistry. Chem. Soc. Rev. 2010, 39, 4146-415.

29. Petrucci, R.; Chiarotto, I.; Mattiello, L.; Passeri, D.; Rossi, M.; Zollo, G.; Feroci, M. Graphene Oxide: A Smart (Starting) Material for Natural Methylxanthines Adsorption and Detection. Molecules 2019, $24,4247$.

30. Lo T. W.B., Aldous L., Compton R. G. The use of nano-carbon as an alternative to multi-walled carbon nanotubes in modified electrodes for adsorptive stripping voltammetry Sensors and Actuators B, 2012, 162, 361-368.

31. Vicentini F. C.; Ravanini A. E.; Figueiredo-Filho L. C.S.; Iniesta J., Banks C. E.; Fatibello-Filho O. Imparting improvements in electrochemical sensors: evaluation of different carbon blacks that give rise to significant improvement in the performance of electroanalytical sensing platforms. Electrochimica Acta, 2015, 157, $125-133$. 
32. Arduini F.; Cinti S.; Mazzaracchio V.; Scognamiglio V.; Amine A.; Moscone D.. Carbon black as an outstanding and affordable nanomaterial for electrochemical (bio)sensor design. Biosensors and Bioelectronics 2020, 156, 112033.

33. Long C.M.; Nascarella M.A.; Valberg P.A. Carbon black vs. black carbon and other airborne materials containing elemental carbon: physical and chemical distinctions. Environ. Pollut. 2013 181, 271-286.

34. Mustafa, F.; Andreescu, S. Nanotechnology-based approaches for food sensing and packaging applications. RSC Adv. 2020, 10, 19309.

35. Xiao, T.; Huang, J.; Wang, D.; Meng, T.; Yang, X. Au and Au-Based nanomaterials: Synthesis and recent progress in electrochemical sensor applications. Talanta 2020, 206, 120210.

36. Cerra S., Salamone T.A., Sciubba F., Marsotto M., Battocchio C., Nappini S., Scaramuzzo F.A., Li Voti R., Sibilia C., Matassa R., Beltrán A.M., Familiari G., Fratoddi I., Study of the interaction mechanism between hydrophilic thiol capped gold nanoparticles and melamine in aqueous medium, Colloids and Surfaces B: Biointerfaces 2021, 203, 111727.

37. Fratoddi I., Cerra S., Salamone T.A., Fioravanti R., Sciubba F., Zampetti E., Macagnano A., Generosi A., Paci B., Scaramuzzo F.A., Matassa R., Familiari G., Battocchio C., Marsotto M., Papa P., Bearzotti A., Functionalized Gold Nanoparticles as an Active Layer for Mercury Vapor Detection at Room Temperature, ACS Applied Nano Materials 2021, 4, 2930-2940.

38. Fratoddi I., Rapa M., Testa G., Venditti I., Scaramuzzo F.A., Vinci G., Response surface methodology for the optimization of phenolic compounds extraction from extra virgin olive oil with functionalized gold nanoparticles. Microchemical Journal 2018, 138, 430-437

39. Kim, S.H. Nanoporous gold: Preparation and applications to catalysis and sensors. Curr. Appl. Phys. 2018, 18, $810-818$.

40. Smart, A.; Crew, A.; Pemberton, R.; Hughes, G.; Doran, O.; Hart, J.P. Screen-printed carbon-based biosensors and their applications in agri-food safety. TrAC Trends Anal. Chem. 2020, 127, 115898.

41. Hughes, G.; Westmacott, K.; Honeychurch, K.C.; Crew, A.; Pemberton, R.M.; Hart, J.P. Recent Advances in the Fabrication and Application of Screen-Printed Electrochemical (Bio)Sensors Based on Carbon Materials for Biomedical, Agri-Food and Environmental Analyses. Biosensors 2016, 6, 50.

42. Trojanowicz, M. Impact of nanotechnology on design of advanced screen-printed electrodes for different analytical applications. TrAC Trends Anal. Chem. 2016, 84, 22-47.

43. Bae J.; Park J.; Kim S.; Cho H.; Kim H. J.; Park S.; Shin D.-S. Tailored hydrogels for biosensor applications. Journal of Industrial and Engineering Chemistry 2020, 891-12.

44. Zouaoui F.; Bourouina-Bacha S.; Bourouina M.; Jaffrezic-Renault N.; Zine N.; Errachid A. Electrochemical sensors based on molecularly imprinted chitosan: A review. TrAC Trends Anal. Chem. 2020, 130, 15982.

45. Denisov, E.T.; Afanas'ev, I.B. Oxidation and Antioxidants in Organic Chemistry and Biochemistry; CRC Press: Andover, MA, USA, 2005.

46. Quideau, S.; Deeux, D.; Douat-Casassus, C.; Pouysegu, L. Plant Polyphenols: Chemical Properties, Biological Activities, and Synthesis. Angew. Chem. Int. Ed. 2011, 50, 586-621.

47. Pandey, K.B.; Rizvi, S.I. Plant Polyphenols as Dietary Antioxidants in Human Health and Disease. Oxid. Med. Cell. Longev. 2009, 2, 270-278.

48. Apak, R.; Demirci Çekiç, S.; Üzer, A.; Çelik, S.E.; Bener, M.; Bekdesser, B.; Can, Z.; Saglam, SS.; Önem, A.N.; Erçag, E. Novel Spectroscopic and Electrochemical Sensors and Nanoprobes for the Characterization of Food and Biological Antioxidants. Sensors 2018, 18, 186.

49. Petrucci, R.; Di Matteo, P.; De Francesco, G.; Mattiello, L.; Perretti, G.; P. Russo. Novel fast identification and determination of free polyphenols in untreated craft beers by HPLC-PDA-ESI-MS/MS in SIR mode. J. Agric. Food Chem. 2020, 68, 7984-7994

50. Panusa, A.; Petrucci, R.; Lavecchia, R.; Zuorro, A. UHPLC-PDA-ESI-TOF/MS Metabolic Profiling and Antioxidant Capacity of Arabica and Robusta Coffee Silverskin: Antioxidants vs Phytotoxins. Food Res. Inter. 2017, 99, 155-165.

51. Petrucci, R.; Di Matteo, P.; Sobolev, A.P.; Liguori, L.; Albanese, D.; Proietti, N.; Bortolami, M.; Russo, P. Impact of Dealcoholisation by Osmotic Distillation on Metabolic Profile, Phenolic Content and Antioxidant Capacity 
of Low Alcoholic Craft Beers with Different Malt Composition. Journal of Agricultural and Food Chemistry, 2021, 69, 4816-4826.

52. Bounegru, A.V.; Apetrei, C. Voltammetric Sensors Based on Nanomaterials for Detection of Caffeic Acid in Food Supplements. Chemosensors 2020, 8, 41.

53. Di Carlo, G.; Curulli, A.; Toro, R.G.; Bianchini, C.; De Caro, T.; Padeletti, G.; Zane, D.; Ingo, G.M. Green Synthesis of Gold-Chitosan Nanocomposites for Caffeic Acid Sensing. Langmuir 2012, 28, 5471-5479.

54. Curulli, A.; Di Carlo, G.; Ingo, G.M.; Riccucci, C.; Zane, D.; Bianchini, C. Chitosan Stabilized Gold NanoparticleModified Au Electrodes for the Determination of Polyphenol Index in Wines: A Preliminary Study. Electroanalysis 2012, 24, 897-904.

55. Di Carlo, G.; Curulli, A.; Trani, A.; Zane, D.; Ingo, G.M. Enhanced electrochemical response of structurally related antioxidant at nanostructured hybrid films. Sens. Actuators B 2014, 191, 703-710.

56. Diaconu, M.; Litescu, S.C.; Radu, G.L. Laccase-MWCNT-chitosan biosensor-A new tool for total polyphenolic content evaluation from in vitro cultivated plants. Sens. Actuator B 2010 145, 800-806.

57. Liu, Y.; Qu, X.; Guo, H.; Chen, H.; Liu, B.; Dong, S. Facile preparation of amperometric laccase biosensor with multifunction based on the matrix of carbon nanotubes-chitosan composite. Biosens. Bioelectron. 2006 21, 21952201.

58. Fernandes, S.C.; de Oliveira, I.W.Z.; Fatibello-Filho, O.; Spinelli, A.; Vieira, I.C. Biosensor based on laccase immobilized on microspheres of chitosan crosslinked with tripolyphosphate. Sens. Actuators B 2008 133, $202-207$.

59. Tan, Y.; Deng, W.; Ge, B.; Xie, Q.; Huang, J.; Yao, S. Biofuel cell and phenolic biosensor based on acid-resistant laccase-glutaraldehyde functionalized chitosan-multiwalled carbon nanotubes nanocomposite film. Biosens. Bioelectron. 2009 24, 2225-2231.

60. Luo, X.L.; Xu, J.J.; Wang, J.L.; Chen, H.Y. Electrochemically deposited nanocomposite of chitosan and carbon nanotubes for biosensor application. Chem. Commun. 2005 16, 2169-2171.

61. Luo, X.L.; Xu, J.J.; Du, Y.; Chen, H.Y. A glucose biosensor based on chitosan-glucose oxidase-gold nanoparticles biocomposite formed by one-step electrodeposition. Anal. Biochem. 2004 334, 284-289.

62. Lu, Y.; Yeap Foo, L. Polyphenolics of salvia-a review, Phytochemistry 2002 59, 117-140.

63. Mohamadi, M.; Mostafavi, A.; Torkzadeh-Mahanic, M. Voltammetric Determination of Rosmarinic Acid on Chitosan/Carbon Nanotube Composite-Modified Carbon Paste Electrode Covered with DNA. Journal of The Electrochemical Society, 2015162 B344-B349.

64. Xu, C.; Cai, H.; He, P.; Fang, Y. Electrochemical detection of sequence-specific DNA using a DNA probe labelled with aminoferrocene and chitosan modified electrode immobilized with ssDNA. Analyst, 2001 126, 62-65.

65. Nadeem, M.; Imran, M.; Aslam Gondal, T.; Shahbaz, A.I.M.; Amir, R.M.; Wasim Sajid, M.; Batool Qaisrani, T.; Atif, M.; Hussain, G.; Salehi, B.; et al. Therapeutic Potential of Rosmarinic Acid: A Comprehensive Review. Appl. Sci. 2019, 9, 3139.

66. Petrucci, R.; Zollo, G.; Curulli, A.; Marrosu, G. A new insight into the oxidative mechanism of caffeine and related methylxanthines in aprotic medium: May caffeine be really considered as an antioxidant? BBA - General Subjects 2018, 1862, 1781-1789.

67. Feroci , M.; Bortolami, M.; Chiarotto, I.; Di Matteo, P.; Mattiello, L.; Pandolfi, F.; Rocco, D.; Petrucci, R. An Insight into the Reactivity of the Electrogenerated Radical Cation of Caffeine. Electrochem. 2020, 1, 44-55.

68. Di Matteo, P.; Bortolami, M.; Feroci, M.; Scarano, V.; Petrucci, R. Electrochemical transformations of methylxanthines in non-aqueous medium. ChemElectroChem 2021, 8, 1-11.

69. Trani, A.; Petrucci, R.; Marrosu, G.; Zane, D.; Curulli, A. Selective electrochemical determination of caffeine at a gold-chitosan nanocomposite sensor: May little change on nanocomposites synthesis affect selectivity? J. Electroanal. Chem. 2017, 788, 99-106.

70. Yang, G.; Zhao, F.; Zeng, B. Facile fabrication of a novel anisotropic gold nanoparticle-chitosan-ionic liquid/graphene modified electrode for the determination of theophylline and caffeine. Talanta 2014, 127, 116-122.

71. Riu, J.; Giussani, B. Electrochemical biosensors for the detection of pathogenic bacteria in food. TrAC Trends Anal. Chem. 2020, 126, 115863.

72. The Commission of the European Communities. Commission Regulation (EC) No 2073/2005 of 15th November 2005 on Microbiological Criteria for Foodstuffs; The Commission of the European Communities: Luxembourg City, Luxembourg, 2005. 
73. US Food and Drug Administration. Bad Bug Book, Foodborne Pathogenic Microorganisms and Natural Toxins, 2nd ed.; FDA: Silver Spring, MD, USA, 2012.

74. Xiang, C.; Li, R.; Adhikari, B.; She, Z.; Li, Y.; Kraatz, H.-B. Sensitive electrochemical detection of Salmonella with chitosan-gold nanoparticles composite film. Talanta 2015, 140, 122-127.

75. Du, Y.; Luo, X.L.; Xu, J.J.; Chen, H.Y. A simple method to fabricate a chitosan-gold nanoparticles film and its application in glucose biosensor. Bioelectrochemistry 200770 342-347.

76. Shi, X.W.; Yang, X.H.; Gaskell, K.J.; Liu, Y.; Kobatake, E.; Bentley, W.E.; Payne, G.F. Reagentless Protein Assembly Triggered by Localized Electrical Signals. Adv. Mater. 2009 21, 984-988.

77. Dinshaw, I.J.; Muniandy, S.; Jyan Teh, S.; Ibrahim, F.; Fen Leo, B.; Lin Thong, K. Development of an aptasensor using reduced graphene oxide chitosan complex to detect Salmonella. J. Electroanal. Chem. 2017, 806, 88-96

78. Choi, W.; Lahiri, I.; Seelaboyina, R.; Kang, Y.S. Synthesis of graphene and its applications: a review. Crit. Rev. Solid State Mater. Sci. 201035 52-71.

79. Justin, R.; Chen, B. Strong and conductive chitosan-reduced graphene oxide nanocomposites for transdermal drug delivery. J. Mater. Chem. B 2014 23759-3770.

80. Güner, A.; Çevik, E.; Senel, M.; Alpsoy, L. An electrochemical immunosensor for sensitive detection of Escherichia coli O157:H7 by using chitosan, MWCNT, polypyrrole with gold nanoparticles hybrid sensing platform. Food Chem. 2017, 229, 358-365.

81. Hills, K. D.; Oliveira, D. A.; Cavallaro, N. D.; Gomes, C. L., McLamore, E.S. Actuation of chitosan-aptamer nanobrush border for pathogen sensing. Analyst, 2018, 143, 1650-1662.

82. Zhao L. Horseradish Peroxidase Labelled-Sandwich Electrochemical Sensor Based on Ionic Liquid-Gold Nanoparticles for Lactobacillus brevis. Micromachines 2021, 12, 75-84.

83. Suresh, L.; Brahman, P.K.; Reddy, K.R.; Bondili, J. Development of an Electrochemical Immunosensor Based on Gold Nanoparticles Incorporated Chitosan Biopolymer Nanocomposite Film for the Detection of Prostate Cancer Using PSA as Biomarker. Enzym. Microb. Technol. 2018, 112, 43-51.

84. World Health Organization (WHO). Food Safety 2021. Available online: https://www.who.int/health-topics/food-safety/ (accessed on 22 February 2021).

85. World Health Organization. Foodborne Disease Outbreaks: Guidelines for Investigation and Control; World Health Organization Publisher: Geneva, Switzerland, 2008.

86. Zhang, X.; Li, C.-R.; Wang, W.-C.; Xue, J.; Huang, Y.-L.; Yang, X.-X.; Tan, B.; Zhou, X.-P.; Shao, C.; Ding, S.-J.; Qiu, J.-F. A novel electrochemical immunosensor for highly sensitive detection of aflatoxin B1 in corn using single-walled carbon nanotubes/chitosan. Food Chemistry 2016 192, 197-202.

87. Pitt, J.I.; Miller, J.D. A Concise History of Mycotoxin Research. J. Agric. Food Chem. 2017, 65, 7021-7033.

88. IARC Working Group on the Evaluation of Carcinogenic Risks to Humans. International Agency for Research on Cancer, Some Traditional Herbal Medicines, Some Mycotoxins, Naphthalene and Styrene; IARC Publisher: Lyon, France, 2002; Volume 82.

89. Li, X.; Falcone, N.; Hossain, M. N.; Kraatz, H.-B.; Chen, X.; Huang, H. Development of a novel label-free impedimetric electrochemical sensor based on hydrogel/chitosan for the detection of ochratoxin A. Talanta 2021226 , 122183.

90. EFSA Panel on Contaminants in the Food Chain (CONTAM). Appropriateness to set a group health-based guidance value for fumonisins and their modified forms. EFSA J. 2018, 16, 5172-5247.

91. EFSA Panel on Contaminants in the Food Chain (CONTAM). Risk assessment of ochratoxin A in food. EFSA J. 2020, 18, 6113-6263.

92. World Health Organization. Human Biomonitoring: Facts and Figures; WHO Regional Office for Europe: Copenhagen, Denmark, 2015.

93. EU Pesticides Database. Available online: https://ec.europa.eu/food/plant/pesticides/eu-pesticides-db_en (accessed on 2 March 2021).

94. EU Legislation on MRLs. Regulation EC 396/2005 and Amendments. Available online: https://ec.europa.eu/food/plant/pesticides/max_residue_levels/eu_rules_en (accessed on 2 March 2021). 
95. Cui, H.-F.; Wu, W.-W.; Li, M.-M.; Song, X.; Lu, Y.; Zhang, T.-T. Highly stable acetylcholinesterase biosensor based on chitosan-TiO2-graphene nanocomposites for detection of organophosphate pesticides. Biosensors and Bioelectronics 2018 99, 223-229.

96. Zhou,H.; Wei, C.; Fang, J.; Fu, L.; Liu, G.; Liu, Q. Poly 3,4-ethylenedioxythiophene and zirconia nanoparticles composite modified sensor for methyl parathion determination. Journal of Electroanalytical Chemistry 2019848 , 113282.

97. Kaur, R.; Rana, S.; Lalit, K.; Singh, P.; Kaur, K. Electrochemical detection of methyl parathion via a novel biosensor tailored on highly biocompatible electrochemically reduced graphene oxide-chitosan-haemoglobin coatings. Biosensors and Bioelectronics 2020 167, 112486.

98. de Matos Morawski, F.; Winiarski, J. P.; Maduro de Campos, C. E.; Parize, A.L.; Jost, C. L. Sensitive simultaneous voltammetric determination of the herbicides diuron and isoproturon at a platinum/chitosan bio-based sensing platform Ecotoxicology and Environmental Safety 2020 206, 111181.

99. Saadati, A.; Hassanpour, S.; Hasanzadeh, M. Lab-on-fruit skin and lab-on-leaf towards recognition of trifluralin using Ag-citrate/GQDs nanocomposite stabilized on the flexible substrate: A new platform for the electroanalysis of herbicides using direct writing of nano-inks and pen-on paper technology. Heliyon 2020, 6, e05779.

100. Neuhold, C. The 'Legislative Backbone' Keeping the Institution Upright? The Role of European Parliament Committees in the EU Policy-Making Process. Eur. Integr. Online Pap. 2001 5, 10.

101. dos Santos Melo, A.M.; Valentim, I.B.; Goulart, M.O.; de Abreu, F.C. Adsorption studies of trifluralin on chitosan and its voltammetric determination on a modified chitosan glassy carbon electrode. J. Braz. Chem. Soc. 200819 (4) 704-710.

102. Ghiasi, T.; Ahmadi, S.; Ahmadi, E.; Talei Bavil Olyai, M.R.; Khodadadi, Z. Novel electrochemical sensor based on modified glassy carbon electrode with graphene quantum dots, chitosan and nickel molybdate nanocomposites for diazinon and optimal design by the Taguchi method. Microchemical Journal 2021 160, 105628.

103. Shi; K.; Shiu, K.-K. Scanning Tunneling Microscopic and Voltammetric Studies of the Surface Structures of an Electrochemically Activated Glassy Carbon Electrode. Anal. Chem. 2002, 74, 879-885.

104. Diamanti-Kandarakis, E.; Bourguignon, J.-P.; Giudice, L.C.; Hauser, R.; Prins, G.S.; Soto, A.M.; Zoeller, R.T.; Gore, A.C. Endocrine-Disrupting Chemicals: An Endocrine Society Scientific Statement. Endocr. Rev. 2009, 30, 293-342.

105. World Health Organization (WHO). State of the Science of Endocrine Disrupting Chemicals-2012; Bergman, A., Heindel, J.J., Jobling, S., Kidd, K.A., Zoeller, R.T., Eds.; United Nations Environment Programme, and the World Health Organization: Geneva, Switzerland, 2013.

106. Anirudhan, T.S.; Athira, V.S.; Chithra Sekhar, V. Electrochemical sensing and nano molar level detection of Bisphenol-A with molecularly imprinted polymer tailored on multiwalled carbon nanotubes. Polymer 2018 146 , 312-320.

107. Chen; H.; Jacobs, O.; Wu, W.; Rüdiger, G.; Schadel, B. Effect of dispersion method on tribological properties of carbon nanotube reinforced epoxy resin composites. Polym. Test. 200726 351-360.

108. Zou, J.; Yuan, M.-M.; Huang, Z.-N.; Chen, X.-Q.; Jiang, X.-Y.; Jiao, F.-P.; Zhou, N.; Zhou, Z.; Yu, J.-G. Highly sensitive and selective determination of bisphenol A in milk samples based on self-assembled graphene nanoplatelets-multiwalled carbon nanotube-chitosan nanostructure. Mater. Sci. Eng. C 2019, 103, 109848.

109. Wang, Y.; Yin, C.; Zhuang, Q. An electrochemical sensor modified with nickel nanoparticle/nitrogen-doped carbon nanosheet nanocomposite for bisphenol A detection. J. Alloys Compd. 2020, 827, 154335.

110. Niu, X.H.; Lan, M.B.; Zhao, H.L.; Chen, C. Highly sensitive and selective nonenzymatic detection of glucose using three-dimensional porous nickel nanostructures. Anal. Chem. 2013853561 e3569.

111. Wang, B.; Li, S.M.; Liu, J.H.; Yu, M. Preparation of nickel nanoparticle/graphene composites for non-enzymatic electrochemical glucose biosensor applications. Mater. Res. Bull. 201449 521-524.

112. Gao, W.B.; Li, Q.; Dou, M.L.; Zhang, Z.P.; Wang, F. Self-supported Ni nanoparticles embedded on nitrogendoped carbon derived from nickel polyphthalocyanine for high-performance non-enzymatic glucose detection. J. Mater. Chem. B 20186 6781-6787.

113. Suginta, W.; Khunkaewla, P.; Schulte, A. Electrochemical biosensor applications of polysaccharides chitin and chitosan. Chem. Rev. 2013113 5458-5479. 
114. Pundir, C. S.; Rawal, R. Determination of sulfite with emphasis on biosensing methods: a review. Anal. Bioanal. Chem. 2013, 405, 3049-3062.

115. Knodel; L. C. Current issues in drug toxicity: Potential health hazards of sulphites. Toxic Subst. Mech. 1997, 3, 309-311.

116. Register, F. Federal Register 1986, 51, 25012-25020.

117. Adeosun, W. A.; Asiri, A. M.; Marwani; H.M. Fabrication of Conductive Polypyrrole Doped Chitosan Thin Film for Sensitive Detection of Sulfite in Real Food and Biological Samples. Electroanalysis 2020, 32, 1725-1736.

118. Matumoto-Pintro, P.T.; Murakami, A.E.; Vital, A.C.P.; Croge, C.; da Silva, D.F.; Ospina-Roja, I.C.; Guerra, A.F.Q.G. Effects of storage time and temperature on lipid oxidation of egg powders enriched with natural antioxidants. Food Chem. 2017228 463-468.

119. Vallo, L.L.; Laxamana, R.T.; Paredes, F.U.; Arellano, I.H.J.; Arco, S.D. Harnessing noncovalent interactions in molecular traps for probable human carcinogen butylated hydroxyanisole. Mater. Lett. 2015 59 317-320.

120. Martín, J.M.P.; Freire, P.F.; Daimiel, L.; Martínez-Botas, J.; Sanchez, C.M.; Lasuncion, M.A.; Peropadre, A.; Hazen, M.J. The antioxidant butylated hydroxyanisole potentiates the toxic effects of propylparaben. Toxicology 201472 195-203.

121. Motia, S.; Bouchikhi, B.; El Bari, N. An electrochemical molecularly imprinted sensor based on chitosan capped with gold nanoparticles and its application for highly sensitive butylated hydroxyanisole analysis in foodstuff products. Talanta 2021223121689.

122. Cui, M.; Liu, S.; Lian, W.; Li, J.; Xu, W.; Huang, J. A molecularly-imprinted electrochemical sensor based on a graphene-Prussian blue composite-modified glassy carbon electrode for the detection of butylated hydroxyanisole in foodstuffs. Analyst 2013138 5949-5955. 